\title{
Efficient Asymmetric Synthesis of a Novel Gastrin
}

\section{Receptor Antagonist AG-041R via Highly}

\section{Stereoselective Alkylation of Oxindole Enolates}

\author{
Takashi Emura, ${ }^{* \dagger}{ }^{\dagger}$ Toru Esaki, ${ }^{\dagger}$ Kazutaka Tachibana, ${ }^{\dagger}$ and Makoto Shimizu ${ }^{\star}$
}

Chemistry Research Dept. 1 Chugai Pharmaceutical Co., LTD., 1-135 Komakado, Gotemba, Shizuoka 412-8513, Japan, and

Department of Chemistry for Materials, Graduate School of Engineering, Mie University, 1577

Kurimamachiya-cho, Tsu, Mie 514-8507, Japan.

emuratks@chugai-pharm.co.jp

Supporting Information

\section{Table of Contents}

General Methods

Experimental and Spectral Data

ORTEP Drawing for the X-ray Structure of 12

Copies of ${ }^{1} \mathrm{H}$ NMR and ${ }^{13} \mathrm{C}$ NMR Spectra
S2

S2-S7

S8

S9-S25 


\section{General Methods}

All reactions were performed under nitrogen atmosphere. All commercially available reagents and solvents were used without further purification unless otherwise noted. Column chromatography was performed with silica gel $(0.040-0.100 \mathrm{~mm})$. The combined organic layers were dried over $\mathrm{Na}_{2} \mathrm{SO}_{4}$. Solvents were evaporated under reduced pressure. All yields given refer to an isolated yield. Diastereomeric ratios were determined by ${ }^{1} \mathrm{H}$ NMR spectra or HPLC analysis using YMC-Pack CN column $(4.6 \times 300)$ with a mobile phase of $n$-Hexane $/ i-\mathrm{PrOH}=99: 1$, and flow rate $0.9 \mathrm{~mL} / \mathrm{min}$. NMR spectra were recorded on a $300 \mathrm{MHz}$ spectrometer. Chemical shifts are reported in ppm. Coupling constants ( $J$ values) are reported in Hertz. HRMS experiments were performed on a high resolution magnetic sector mass spectrometer.

\section{Experimental and Spectral Data}

[(R)-2-Oxo-1-(2-oxo-ethyl)-3-(3-p-tolyl-ureido)-2,3-dihydro-1H-indol-3-yl]-acetic acid (1R,2S,5R)-2-isopropyl-5-methyl-cyclohexyl ester (11). To a solution of 9 (210 $\mathrm{mg}, 0.386 \mathrm{mmol})$ in acetone $(10 \mathrm{~mL})$ and water $(10 \mathrm{~mL})$ was added $2 \mathrm{~N} \mathrm{HCl}(0.5 \mathrm{~mL})$. The mixture was refluxed for $14 \mathrm{~h}$. To the reaction mixture was added saturated $\mathrm{NaHCO}_{3}$ solution, followed by removal of solvent in vacuo. The mixture was extracted with diethyl ether $(20 \mathrm{ml} \times 2)$. The combined organic layers were dried over $\mathrm{MgSO}_{4}$ and then concentrated under vacuum. The crude mixture was purified by silica gel chromatography to give title compound $\mathbf{1 1}$ as a white amorphous powder (142 mg, 78\% yield): ${ }^{1} \mathrm{H}$ NMR (300 MHz, $\left.\mathrm{CDCl}_{3}\right) \delta 9.70(\mathrm{~s}, 1 \mathrm{H}), 7.30(\mathrm{dd}, J=7.5,0.9 \mathrm{~Hz}, 1 \mathrm{H}), 7.25(\mathrm{ddd}, J=7.8,7.8,1.2 \mathrm{~Hz}, 1 \mathrm{H})$, $7.09(\mathrm{~d}, J=8.4 \mathrm{~Hz}, 2 \mathrm{H}), 7.06-6.94(\mathrm{~m}, 5 \mathrm{H}), 6.71(\mathrm{~d}, J=7.8 \mathrm{~Hz}, 1 \mathrm{H}), 4.64(\mathrm{~d}, J=18.6 \mathrm{~Hz}, 1 \mathrm{H}), 4.63$ $(\mathrm{dd}, J=11.0,6.6 \mathrm{~Hz}, 1 \mathrm{H}), 4.48(\mathrm{~d}, J=18.3 \mathrm{~Hz}, 1 \mathrm{H}), 2.95(\mathrm{~d}, J=15.4 \mathrm{~Hz}, 1 \mathrm{H}), 2.60(\mathrm{~d}, J=15.4 \mathrm{~Hz}$, 1H), $2.26(\mathrm{~s}, 3 \mathrm{H}), 1.91-1.82(\mathrm{~m}, 1 \mathrm{H}), 1.70-1.56(\mathrm{~m}, 3 \mathrm{H}), 1.52-1.32(\mathrm{~m}, 1 \mathrm{H}), 1.31-1.18(\mathrm{~m}, 1 \mathrm{H}), 1.08-$ $0.74(\mathrm{~m}, 2 \mathrm{H}), 0.89(\mathrm{~d}, J=6.6 \mathrm{~Hz}, 3 \mathrm{H}), 0.82(\mathrm{~d}, J=7.0 \mathrm{~Hz}, 3 \mathrm{H}), 0.63(\mathrm{~d}, J=6.9 \mathrm{~Hz}, 3 \mathrm{H}) ;{ }^{13} \mathrm{C} \mathrm{NMR}(75$ $\left.\mathrm{MHz}, \mathrm{CDCl}_{3}\right) \delta 196.9,176.1,169.4,153.9,141.8,135.2,133.1,129.4,129.3,129.1,123.2,123.0,120.7$, 108.5, 75.6, 59.3, 49.9, 46.7, 41.1, 40.8, 34.1, 31.5, 26.1, 23.3, 22.1, 20.9, 20.8, 16.2. HRMS m/z [M + $\mathrm{H}]^{+}$calcd for $\mathrm{C}_{30} \mathrm{H}_{38} \mathrm{~N}_{3} \mathrm{O}_{5}, 520.2811$; found, 520.2806 . 
(1R,2S,5R)-2-isopropyl-5-methyl-cyclohexyl ester (12). To a solution of 11 (448 mg, $0.862 \mathrm{mmol}$ ) in $\mathrm{MeOH}(5.0 \mathrm{~mL})$ was added sodium borohydride $(16.3 \mathrm{mg}, 0.431 \mathrm{mmol})$. After stirring at $\mathrm{rt}$ for $1 \mathrm{~h}$, water was added and then extracted with methylene chloride $(20 \mathrm{ml} \times 2)$. The combined organic layers were dried over $\mathrm{Na}_{2} \mathrm{SO}_{4}$ and then concentrated in vacuo. The crude mixture was purified by silica gel chromatography to give the title compound $\mathbf{1 2}$ as a white crystal (443 mg, 94\% yield): $\mathrm{mp} 155-157{ }^{\circ} \mathrm{C}$; ${ }^{1} \mathrm{H}$ NMR $\left(300 \mathrm{MHz}, \mathrm{CDCl}_{3}\right) \delta 7.33-7.25(\mathrm{~m}, 2 \mathrm{H}), 7.09-6.96(\mathrm{~m}, 5 \mathrm{H}), 6.92(\mathrm{~d}, J=7.5 \mathrm{~Hz}, 1 \mathrm{H}), 6.89(\mathrm{~s}$, 1H), $6.84(\mathrm{~s}, 1 \mathrm{H}), 4.62$ (ddd, $J=10.8,10.8,4.4 \mathrm{~Hz}, 1 \mathrm{H}), 4.26-4.15(\mathrm{~m}, 1 \mathrm{H}), 4.04-3.85$ (m, 3H), 3.80$3.69(\mathrm{~m}, 1 \mathrm{H}), 3.03(\mathrm{~d}, J=15.4 \mathrm{~Hz}, 1 \mathrm{H}), 2.68(\mathrm{~d}, J=15.3 \mathrm{~Hz}, 1 \mathrm{H}), 2.24(\mathrm{~s}, 3 \mathrm{H}), 1.89-1.80(\mathrm{~m}, 1 \mathrm{H}), 1.71$ $(\mathrm{s}, 1 \mathrm{H}), 1.70-1.52(\mathrm{~m}, 3 \mathrm{H}), 1.51-1.34(\mathrm{~m}, 1 \mathrm{H}), 1.28-1.16(\mathrm{~m}, 1 \mathrm{H}), 1.06-0.72(\mathrm{~m}, 3 \mathrm{H}), 0.88(\mathrm{~d}, J=6.6$ $\mathrm{Hz}, 3 \mathrm{H}), 0.82(\mathrm{~d}, J=7.0 \mathrm{~Hz}, 3 \mathrm{H}) 0.60(\mathrm{~d}, J=7.0 \mathrm{~Hz}, 3 \mathrm{H}) ;{ }^{13} \mathrm{C} \mathrm{NMR}\left(75 \mathrm{MHz}, \mathrm{CDCl}_{3}\right) \delta 176.4,169.5$, $153.9,142.8,134.9,133.4,129.4,129.22,129.17,123.1,122.7,120.9,109.1,75.6,59.05,58.96,46.8$, 43.3, 40.8, 40.7, 34.1, 31.4, 26.1, 23.3, 22.1, 20.9, 20.8, 16.2. HRMS m/z $[\mathrm{M}+\mathrm{H}]^{+}$calcd for $\mathrm{C}_{30} \mathrm{H}_{40} \mathrm{~N}_{3} \mathrm{O}_{5}$, 522.2968; found, 522.2968. The crystal for X-ray analysis was obtained by recrystallization from ethyl acetate and hexane.

General procedure for the asymmetric alkylation. To a solution of oxindole derivatives $(0.10$ $\mathrm{mmol})$ in THF $(0.40 \mathrm{~mL})$ was added LiHMDS $(0.10 \mathrm{mmol})$ at $0{ }^{\circ} \mathrm{C}$ followed by the addition of bromoacetic acid ester $(0.110 \mathrm{mmol})$. After stirring for $5 \mathrm{~h}$, aqueous $\mathrm{NH}_{4} \mathrm{Cl}$ was added and extracted with methylene chloride $(20 \mathrm{ml} \times 2)$. The combined organic layers were dried over $\mathrm{Na}_{2} \mathrm{SO}_{4}$ and then concentrated in vacuo. The crude mixture was purified by silica gel chromatography to give the title compound.

1-(1-Methyl-2-oxo-2,3-dihydro-1H-indol-3-yl)-3-p-tolyl-urea (14a). To a solution of oxime 1methyl-1H-indole-2,3-dione, 3-(O-methyloxime) $(511 \mathrm{mg}, 2.69 \mathrm{mmol})$ in acetonitrile was added 5\% palladium on carbon $(50 \mathrm{mg})$. The mixture was stirred under hydrogen under atmospheric pressure at ambient temperature for $2 \mathrm{~h}$. After removal of the palladium on carbon, $p$-tolyl isocyanate (358 $\mathrm{mg}, 2.69$ mmol) was added at ambient temperature. The mixture was stirred for $1 \mathrm{~h}$ during which time a solid was 
generated. The cake was collected and washed with acetonitrile and then dried under reduced pressure to give the title compound 14a as a white crystal (690 mg, 87\% yield): mp $260{ }^{\circ} \mathrm{C}$ (dec.); ${ }^{1} \mathrm{H}$ NMR $(300$ MHz, DMSO- $\left.d_{6}\right) \delta 8.67(\mathrm{~s}, 1 \mathrm{H}), 7.30-7.21(\mathrm{~m}, 4 \mathrm{H}), 7.04-6.89(\mathrm{~m}, 5 \mathrm{H}), 5.02(\mathrm{~d}, J=7.6 \mathrm{~Hz}, 1 \mathrm{H}), 3.11(\mathrm{~s}$, 3H), $2.19(\mathrm{~s}, 3 \mathrm{H}) ;{ }^{13} \mathrm{C}$ NMR (75 MHz, DMSO-d $\left.{ }_{6}\right) \delta 174.3,154.2,143.5,137.2,129.8,128.7,128.0$, 127.8, 122.9, 121.7, 117.6, 108.0, 52.5, 26.1, 20.2. HRMS m/z $[\mathrm{M}+\mathrm{H}]^{+}$calcd for $\mathrm{C}_{17} \mathrm{H}_{18} \mathrm{~N}_{3} \mathrm{O}_{2}$, 296.1399; found, 296.1393.

(1-Methyl-2-oxo-2,3-dihydro-1H-indol-3-yl)-carbamic acid tert-butyl ester (14b). To a solution of 1-methyl-1H-indole-2,3-dione, 3-(O-methyloxime) $(310 \mathrm{mg}, 1.63 \mathrm{mmol})$ and $\mathrm{BOC}_{2} \mathrm{O}(391 \mathrm{mg}, 1.79$ mmol) in acetonitrile was added $5 \%$ palladium on carbon $(20 \mathrm{mg})$. The mixture was stirred under hydrogen under atmospheric pressure at ambient temperature for $2 \mathrm{~h}$. After removal of the palladium on carbon, the solvent was removed under reduced pressure. The mixture was purified by a silica gel column to give the title product 14b. (394 mg, 92\% yield): mp 122-123 ${ }^{\circ} \mathrm{C} ;{ }^{1} \mathrm{H}$ NMR (300 MHz, $\left.\mathrm{CDCl}_{3}\right) \delta 7.39(\mathrm{~d}, J=7.2 \mathrm{~Hz}, 1 \mathrm{H}), 7.31(\mathrm{dd}, J=7.9,7.8 \mathrm{~Hz}, 1 \mathrm{H}), 7.07(\mathrm{ddd}, J=7.8,7.3,1.1 \mathrm{~Hz}, 1 \mathrm{H})$, $6.82(\mathrm{~d}, J=7.8 \mathrm{~Hz}, 1 \mathrm{H}), 5.20-5.00(\mathrm{~m}, 2 \mathrm{H}), 3.22(\mathrm{~s}, 3 \mathrm{H}), 1.45$ (brs, 9H); ${ }^{13} \mathrm{C} \mathrm{NMR}\left(75 \mathrm{MHz}, \mathrm{CDCl}_{3}\right) \delta$ $174.3,155.7,143.4,128.9,126.7,124.3,122.7,108.1,80.4,53.6,28.3,26.5 . \mathrm{HRMS} \mathrm{m} / \mathrm{z}[\mathrm{M}+\mathrm{H}]^{+}$ calcd for $\mathrm{C}_{14} \mathrm{H}_{19} \mathrm{~N}_{2} \mathrm{O}_{3}, 263.1396$; found, 263.1390.

(1-Methyl-2-oxo-2,3-dihydro-1H-indol-3-yl)-carbamic acid (14c). To a solution of 1-methyl-1Hindole-2,3-dione, 3-(O-methyloxime) $(511 \mathrm{mg}, 2.69 \mathrm{mmol})$ in acetonitrile $(30 \mathrm{~mL})$ was added 5\% palladium on carbon $(50 \mathrm{mg})$. The mixture was stirred under hydrogen under atmospheric pressure at ambient temperature for $2 \mathrm{~h}$. After removal of the palladium carbon by filtration, $\mathrm{N}, \mathrm{N}$-dimethylaniline (391 mg, $3.22 \mathrm{mmol}$ ) and methyl chloroformate $(305 \mathrm{mg}, 3.22 \mathrm{mmol}$ ) were added successively at ambient temperature. The mixture was stirred for $0.5 \mathrm{~h}$. The mixture was extracted with AcOEt. The organic layer was washed with $2 \mathrm{~N} \mathrm{HCl}$, saturated $\mathrm{NaCl}$, and saturated $\mathrm{NaHCO}_{3}$ successively. After removal of the solvent in vacuo, a crystalline product was obtained. The crystalline mixture was washed with 1:1 AcOEt/hexane, affording the title product 14c. (295 mg, 50\% yield): mp $158-159{ }^{\circ} \mathrm{C} ;{ }^{1} \mathrm{H} \mathrm{NMR}$ 
$\left(300 \mathrm{MHz}, \mathrm{CDCl}_{3}\right) \delta 7.37-7.25(\mathrm{~m}, 2 \mathrm{H}), 7.04(\mathrm{ddd}, J=7.5,7.5,0.2 \mathrm{~Hz}, 1 \mathrm{H}), 6.80(\mathrm{~d}, J=7.8 \mathrm{~Hz}, 1 \mathrm{H})$, $5.76(\mathrm{br}, 1 \mathrm{H}), 5.00(\mathrm{~d}, J=7.9 \mathrm{~Hz}, 1 \mathrm{H}), 3.67(\mathrm{~s}, 3 \mathrm{H}), 3.18(\mathrm{~s}, 3 \mathrm{H}) ;{ }^{13} \mathrm{C} \mathrm{NMR}\left(75 \mathrm{MHz}, \mathrm{CDCl}_{3}\right) \delta 174.1$, 156.7, 143.4, 129.1, 126.2, 124.1, 122.8, 108.1, 53.8, 52.6, 26.5. HRMS m/z $[\mathrm{M}+\mathrm{H}]^{+}$calcd for $\mathrm{C}_{11} \mathrm{H}_{13} \mathrm{~N}_{2} \mathrm{O}_{3}, 221.0926$; found, 221.0917.

(3-Methoxycarbonylamino-1-methyl-2-oxo-2,3-dihydro-1H-indol-3-yl)-acetic acid (1R,2S,5R)-2isopropyl-5-methyl-cyclohexyl ester $(\mathbf{1 5 c}+\mathbf{1 6 c})$. General procedure was followed with 14c. The diastereomeric ratio was determined to be $72: 28$ by comparison of one of geminal protons in ${ }^{1} \mathrm{H}$ NMR analysis of the crude product $\left(-\mathrm{CH}_{2} \mathrm{CO}_{2} l\right.$-Menthyl, major $\delta 2.55 \mathrm{ppm}$, minor $\left.\delta 2.50 \mathrm{ppm}\right)$. The title compounds 15c and 16c was obtained in 58\% yield as an inseparable mixture of diastereomers as a colorless oil: ${ }^{1} \mathrm{H}$ NMR $\left(300 \mathrm{MHz}, \mathrm{CDCl}_{3}\right) \delta$ 7.35-7.24 (m, 2H), 7.06-6.98 (m, 1H), 6.88-6.80 (m, 1.3 H), 6.61 (brs, 0.7H), 4.80-4.62 (m, 1H), $3.55(\mathrm{~s}, 3 \mathrm{H}), 3.27(\mathrm{~s}, 3 \mathrm{H}), 3.00(\mathrm{~d}, J=15.3 \mathrm{~Hz}, 0.7 \mathrm{H}), 2.97(\mathrm{~d}$, $J=15.3 \mathrm{~Hz}, 0.3 \mathrm{H}), 2.55(\mathrm{~d}, J=15.3 \mathrm{~Hz}, 0.7 \mathrm{H}), 2.50(\mathrm{~d}, J=15.3 \mathrm{~Hz}, 0.3 \mathrm{H}), 1.96-1.87(\mathrm{~m}, 1 \mathrm{H}), 1.78-$ $1.56(\mathrm{~m}, 3 \mathrm{H}), 1.55-1.36(\mathrm{~m}, 1 \mathrm{H}), 1.35-1.21(\mathrm{~m}, 1 \mathrm{H}), 1.12-0.8(\mathrm{~m}, 3 \mathrm{H}), 0.90(\mathrm{~d}, J=6.6 \mathrm{~Hz}, 0.9 \mathrm{H}), 0.89$ $(\mathrm{d}, J=6.4 \mathrm{~Hz}, 2.1 \mathrm{H}), 0.85(\mathrm{~d}, J=7.0 \mathrm{~Hz}, 2.1 \mathrm{H}), 0.79(\mathrm{~d}, J=6.9 \mathrm{~Hz}, 0.9 \mathrm{H}), 0.73(\mathrm{~d}, J=6.9 \mathrm{~Hz}, 0.9 \mathrm{H})$, $0.69(\mathrm{~d}, J=7.0 \mathrm{~Hz}, 2.1 \mathrm{H}) ;{ }^{13} \mathrm{C} \mathrm{NMR}\left(75 \mathrm{MHz}, \mathrm{CDCl}_{3}\right) \delta 174.9,169.3,155.0,143.4,129.4,128.7$, 123.3, 123.0, 122.7, 122.6, 108.3, 75.7, 75.6, 59.1, 52.4, 46.8, 46.7, 40.8, 40.7, 40.6, 34.1, 31.45, 31.40, 26.7, 26.2, 25.9, 23.3, 22.0, 20.7, 16.3, 16.1. HRMS m/z $[\mathrm{M}+\mathrm{H}]^{+}$calcd for $\mathrm{C}_{23} \mathrm{H}_{33} \mathrm{~N}_{2} \mathrm{O}_{5}, 417.2389$; found, 417.2390.

$N$-(1-Methyl-2-oxo-2,3-dihydro-1H-indol-3-yl)-benzamide (14d). To a solution of 1-methyl-1Hindole-2,3-dione, 3-(O-methyloxime) (419 mg, $2.20 \mathrm{mmol})$ in acetonitrile $(25 \mathrm{~mL})$ was added 5\% palladium on carbon $(23 \mathrm{mg}$ ). The mixture was stirred under hydrogen under atmospheric pressure at ambient temperature for $1.5 \mathrm{~h}$. After removal of the palladium carbon by filtration, N,N-dimethylaniline (319 mg, $2.64 \mathrm{mmol}$ ) and benzoyl chloride (340 mg, $2.42 \mathrm{mmol}$ ) were added successively at ambient temperature. The mixture was stirred for $0.5 \mathrm{~h}$. The mixture was extracted with AcOEt. The organic layer was washed with $2 \mathrm{~N} \mathrm{HCl}$, saturated $\mathrm{NaCl}$, and saturated $\mathrm{NaHCO}_{3}$, successively. After removal of 
the solvent in vacuo, a crystalline product was obtained. The crystalline mixture was washed with 1:1 AcOEt:Hexane, affording the title product 14d. (577 mg, 98\%): mp 190-191 ${ }^{\circ} \mathrm{C} ;{ }^{1} \mathrm{H}$ NMR (300 MHz, $\left.\mathrm{CDCl}_{3}\right) \delta 7.85(\mathrm{~m}, 2 \mathrm{H}), 7.52(\mathrm{dddd}, J=7.5,6.9,1.5,1.4 \mathrm{~Hz}, 1 \mathrm{H}), 7.47-7.38(\mathrm{~m}, 3 \mathrm{H}), 7.34(\mathrm{dddd}, J=$ 7.7, 7.6, 1.2, $0.7 \mathrm{~Hz}, 1 \mathrm{H}), 7.08(\mathrm{ddd}, J=7.6,7.3,1.1 \mathrm{~Hz}, 1 \mathrm{H}), 6.87(\mathrm{~d}, J=7.8 \mathrm{~Hz}, 1 \mathrm{H}), 6.71(\mathrm{~d}, J=7.0$ $\mathrm{Hz}, 1 \mathrm{H}), 5.57(\mathrm{~d}, J=7.3 \mathrm{~Hz}, 1 \mathrm{H}), 3.27(\mathrm{~s}, 3 \mathrm{H}) ;{ }^{13} \mathrm{C} \mathrm{NMR}\left(75 \mathrm{MHz}, \mathrm{CDCl}_{3}\right) \delta 174.4,167.3,143.5,132.8$, $131.7,129.0,128.3,127.1,126.5,124.4,123.0,108.2,53.2,26.6 . \mathrm{HRMS} \mathrm{m} / \mathrm{z}[\mathrm{M}+\mathrm{H}]^{+}$calcd for $\mathrm{C}_{16} \mathrm{H}_{15} \mathrm{~N}_{2} \mathrm{O}_{2}$, 267.1134; found, 267.1124.

\section{(3-Benzoylamino-1-methyl-2-oxo-2,3-dihydro-1H-indol-3-yl)-acetic acid (1R,2S,5R)-2-isopropyl-}

5-methyl-cyclohexyl ester $(\mathbf{1 5 d}+\mathbf{1 6 d})$. General procedure was followed with 14d, 1.2 equivalent of base and 1.3 equivalent of $l$-menthyl bromoacetate. The diastereomeric ratio was determined to be $95: 5$ by comparison of one of geminal protons in ${ }^{1} \mathrm{H}$ NMR analysis of the crude product $\left(-\mathrm{CH}_{2} \mathrm{CO}_{2} l\right.$-Menthyl, major $\delta 2.54 \mathrm{ppm}$, minor $\delta 2.51 \mathrm{ppm}$ ). The title compounds $\mathbf{1 5 d}$ and $\mathbf{1 6 d}$ was obtained in $82 \%$ yield as an inseparable mixture of diastereomers as a colorless oil: ${ }^{1} \mathrm{H}$ NMR $\left(300 \mathrm{MHz}, \mathrm{CDCl}_{3}\right) \delta 8.58(\mathrm{~s}, 1 \mathrm{H})$, 7.85-7.78 (m, 2H), 7.52-7.45 (m, 1H), 7.44-7.36 (m, 2H), 7.32 (ddd, $J=7.8,7.6,1.2 \mathrm{~Hz}, 1 \mathrm{H}), 7.27-$ $7.22(\mathrm{~m}, 1 \mathrm{H}), 7.00(\mathrm{ddd}, J=7.6,7.5,0.9 \mathrm{~Hz}, 1 \mathrm{H}), 6.90(\mathrm{~d}, J=7.8 \mathrm{~Hz}, 1 \mathrm{H}), 4.79(\mathrm{ddd}, J=11.0,10.8,1.3$ Hz, 1H), $3.33(\mathrm{~s}, 3 \mathrm{H}), 3.12(\mathrm{~d}, J=15.3 \mathrm{~Hz}, 1 \mathrm{H}), 2.54(\mathrm{~d}, J=15.3 \mathrm{~Hz}, 1 \mathrm{H}), 2.07-1.98(\mathrm{~m}, 1 \mathrm{H}), 1.86-1.62$ (m, 3H), 1.60-1.42 (m, 1H), 1.40-1.28 (m, 1H), 1.14-0.80 (m, 3H), $0.92(\mathrm{~d}, J=6.6 \mathrm{~Hz}, 3 \mathrm{H}), 0.86(\mathrm{~d}, J$ $=7.0 \mathrm{~Hz}, 3 \mathrm{H}), 0.77(\mathrm{~d}, J=7.0 \mathrm{~Hz}, 3 \mathrm{H}) ;{ }^{13} \mathrm{C} \mathrm{NMR}\left(75 \mathrm{MHz}, \mathrm{CDCl}_{3}\right) \delta 174.5,170.7,165.5,143.4,132.6$, $131.7,129.3,128.6,128.3,127.1,122.6,122.5,108.4,76.1,59.2,46.8,40.9,40.2,34.1,31.5,26.9,26.4$, 23.5, 22.1, 20.7, 16.4. HRMS m/z $[\mathrm{M}+\mathrm{H}]^{+}$calcd for $\mathrm{C}_{28} \mathrm{H}_{35} \mathrm{~N}_{2} \mathrm{O}_{4}, 463.2597$; found, 463.2595.

$N$-(1-Methyl-2-oxo-2,3-dihydro-1H-indol-3-yl)-acetamide (14e). To a solution of 1-methyl-1Hindole-2,3-dione, 3-(O-methyloxime) (406 mg, $2.13 \mathrm{mmol})$ in acetonitrile $(25 \mathrm{~mL})$ was added 5\% palladium on carbon $(50 \mathrm{mg})$. The mixture was stirred under hydrogen under atmospheric pressure at ambient temperature for $1.5 \mathrm{~h}$. After removal of the palladium carbon by filtration, N,N-dimethylaniline (311 $\mathrm{mg}, 2.56 \mathrm{mmol})$ and acetic anhydride $(234 \mathrm{mg}, 2.34 \mathrm{mmol})$ were added successively at ambient 
temperature. The mixture was stirred for $0.5 \mathrm{~h}$. The mixture was extracted with AcOEt. The organic layer was washed with $2 \mathrm{~N} \mathrm{HCl}$, saturated $\mathrm{NaCl}$ and saturated $\mathrm{NaHCO}_{3}$ successively. After removal of the solvent in vacuo, a crystalline product was obtained. The crystalline mixture was washed with 1:1 AcOEt/hexane, affording the title product 14e. (242 mg, 56\%): $\mathrm{mp} 205-207{ }^{\circ} \mathrm{C} ;{ }^{1} \mathrm{H} \mathrm{NMR}(300 \mathrm{MHz}$, DMSO- $\left.d_{6}\right) \delta 8.65(\mathrm{~d}, J=8.2 \mathrm{~Hz}, 1 \mathrm{H}), 7.29(\mathrm{dddd}, J=7.8,7.6,1.1,1.1 \mathrm{~Hz}, 1 \mathrm{H}), 7.17(\mathrm{~d}, J=7.3 \mathrm{~Hz}, 1 \mathrm{H})$, $7.01(\mathrm{dd}, J=7.7,7.3 \mathrm{~Hz}, 1 \mathrm{H}), 6.98(\mathrm{~d}, J=7.8 \mathrm{~Hz}, 1 \mathrm{H}), 5.15(\mathrm{~d}, J=8.1 \mathrm{~Hz}, 1 \mathrm{H}), 3.12(\mathrm{~s}, 3 \mathrm{H}), 1.89$ (s, $3 \mathrm{H}) ;{ }^{13} \mathrm{C}$ NMR $\left(75 \mathrm{MHz}, \mathrm{DMSO}-d_{6}\right) \delta 173.5,169.0,143.6,128.3,127.0,123.1,121.8,108.1,51.7,26.1$, 22.2. HRMS m/z [M + H] calcd for $\mathrm{C}_{11} \mathrm{H}_{13} \mathrm{~N}_{2} \mathrm{O}_{2}, 205.0977$; found, 205.0971.

(3-Acetylamino-1-methyl-2-oxo-2,3-dihydro-1H-indol-3-yl)-acetic acid (1R,2S,5R)-2-isopropyl-5methyl-cyclohexyl ester $(\mathbf{1 5 e}+\mathbf{1 6 e})$. General procedure was followed with 14e, 1.2 equivalent of base and 1.3 equivalent of $l$-menthyl bromoacetate. The diastereomeric ratio was determined to be $84: 16$ by comparison of one of geminal protons in ${ }^{1} \mathrm{H}$ NMR analysis of the crude product $\left(-\mathrm{CH}_{2} \mathrm{CO}_{2} l\right.$-Menthyl, major $\delta 2.46 \mathrm{ppm}$, minor $\delta 2.43 \mathrm{ppm}$ ). The title compound 15e and $\mathbf{1 6 e}$ was obtained in $69 \%$ yield as an inseparable mixture of diastereomers as a colorless oil: ${ }^{1} \mathrm{H}$ NMR $\left(300 \mathrm{MHz}, \mathrm{CDCl}_{3}\right) \delta 7.51$ (brs, $\left.1 \mathrm{H}\right)$, 7.29 (ddd, $J=7.8,7.6,1.4 \mathrm{~Hz}, 1 \mathrm{H}), 7.23$ (ddd, $J=7.9,1.2,0.5 \mathrm{~Hz}, 1 \mathrm{H}), 7.00$ (ddd, $J=7.6,7.5,0.9 \mathrm{~Hz}$, 1H), $6.85(\mathrm{~d}, J=7.8 \mathrm{~Hz}, 1 \mathrm{H}), 4.71(\mathrm{ddd}, J=11.0,10.8,4.4 \mathrm{~Hz}, 1 \mathrm{H}), 3.26(\mathrm{~s}, 3 \mathrm{H}), 2.98(\mathrm{~d}, J=15.3 \mathrm{~Hz}$, 1H), $2.46(\mathrm{~d}, J=15.3 \mathrm{~Hz}, 1 \mathrm{H}), 1.95(\mathrm{~s}, 3 \mathrm{H}), 2.00-1.90(\mathrm{~m}, 1 \mathrm{H}), 1.80-1.58(\mathrm{~m}, 3 \mathrm{H}), 1.56-1.39(\mathrm{~m}, 1 \mathrm{H})$, $1.36-1.22(\mathrm{~m}, 1 \mathrm{H}), 1.12-0.76(\mathrm{~m}, 3 \mathrm{H}), 0.90(\mathrm{~d}, J=6.4 \mathrm{~Hz}, 3 \mathrm{H}), 0.85(\mathrm{~d}, J=7.0 \mathrm{~Hz}, 3 \mathrm{H}), 0.72(\mathrm{~d}, J=$ $6.9 \mathrm{~Hz}, 3 \mathrm{H}) ;{ }^{13} \mathrm{C} \mathrm{NMR}\left(75 \mathrm{MHz}, \mathrm{CDCl}_{3}\right) \delta 174.7,170.0,168.8,143.4,129.2,128.5,122.9,122.5,108.3$, $75.9,59.1,46.9,40.9,40.2,34.1,31.5,26.8,26.3,23.4,22.8,22.1,20.8,16.4 . \mathrm{HRMS} \mathrm{m} / \mathrm{z}[\mathrm{M}+\mathrm{H}]^{+}$ calcd for $\mathrm{C}_{23} \mathrm{H}_{33} \mathrm{~N}_{2} \mathrm{O}_{4}, 401.2440$; found, 401.2443. 
ORTEP Drawing for the X-ray Structure of 12.

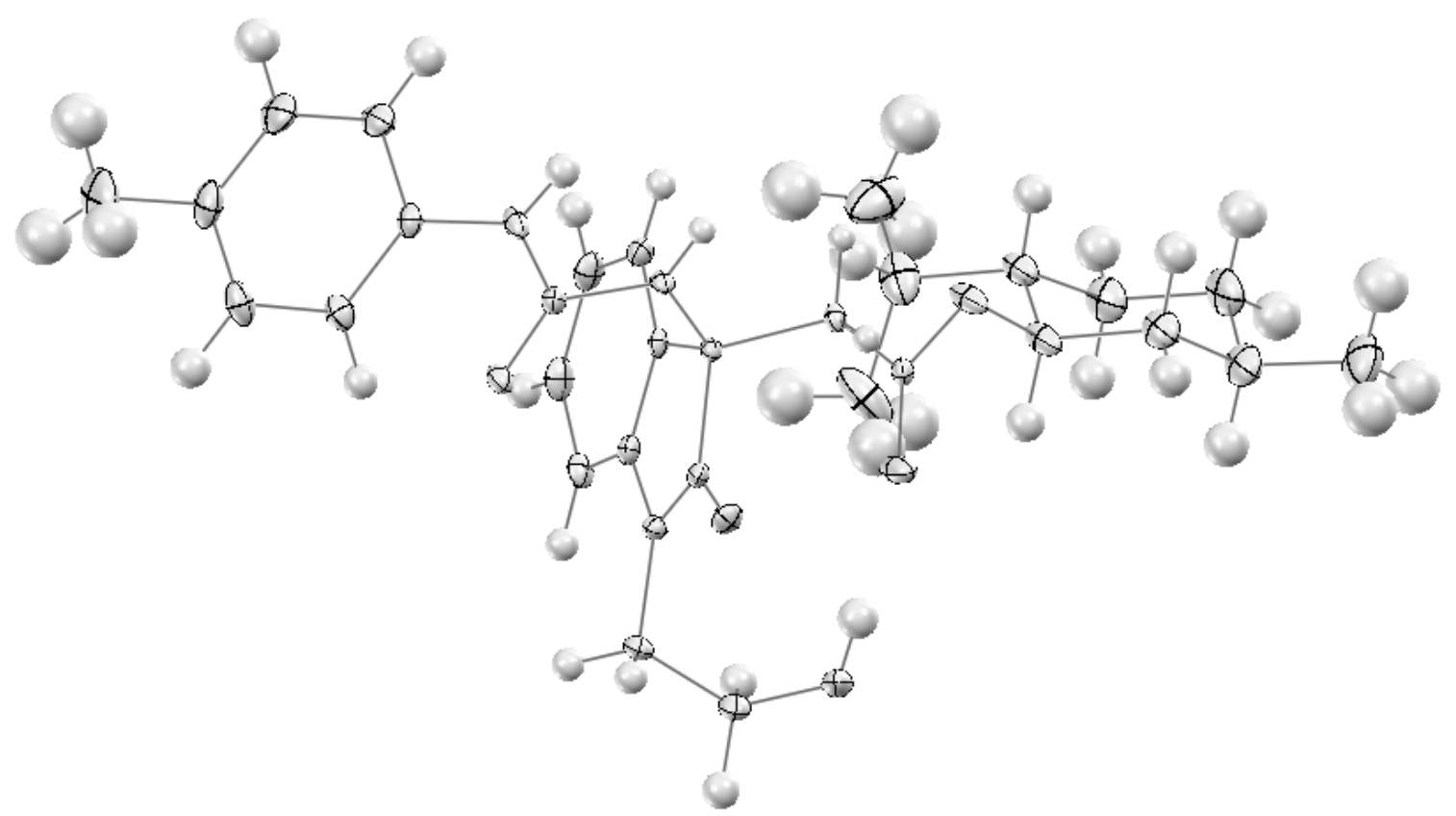



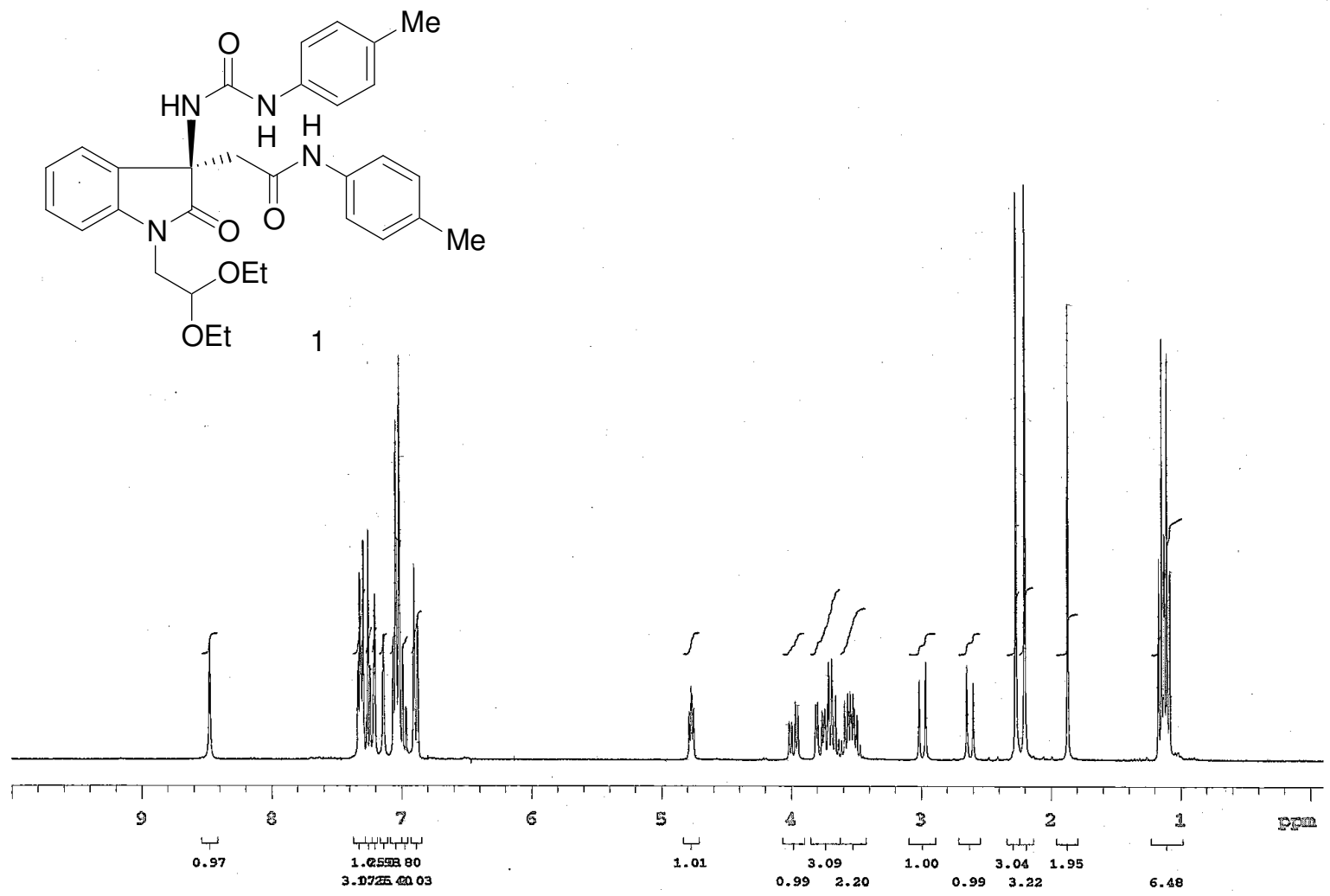

C13 STMIDDARD DRRAHETLER

pulse sequance: в2pu1

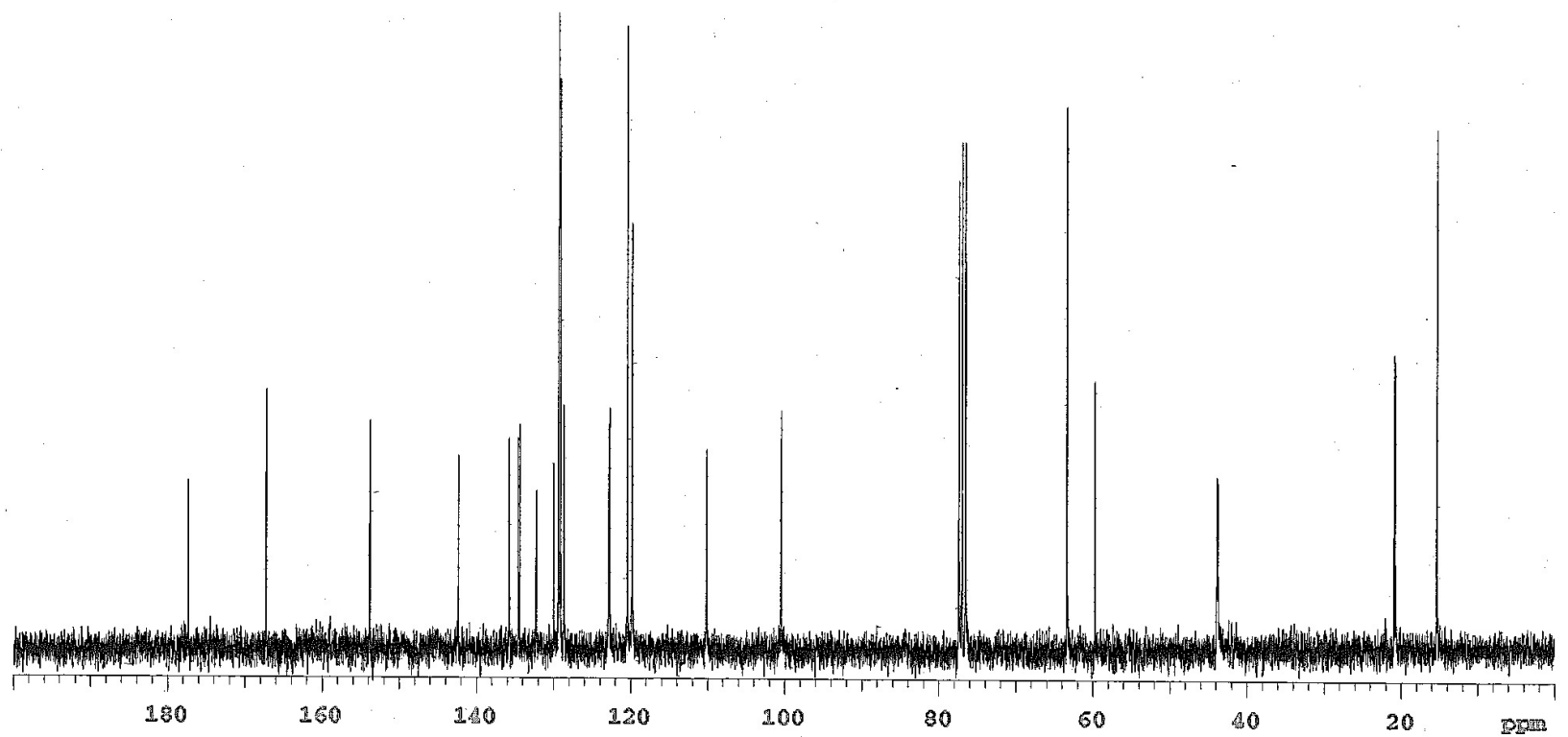


<smiles>CCOC(CN1C(=O)C(NC(=O)Nc2ccc(C)cc2)c2ccccc21)OCC</smiles>

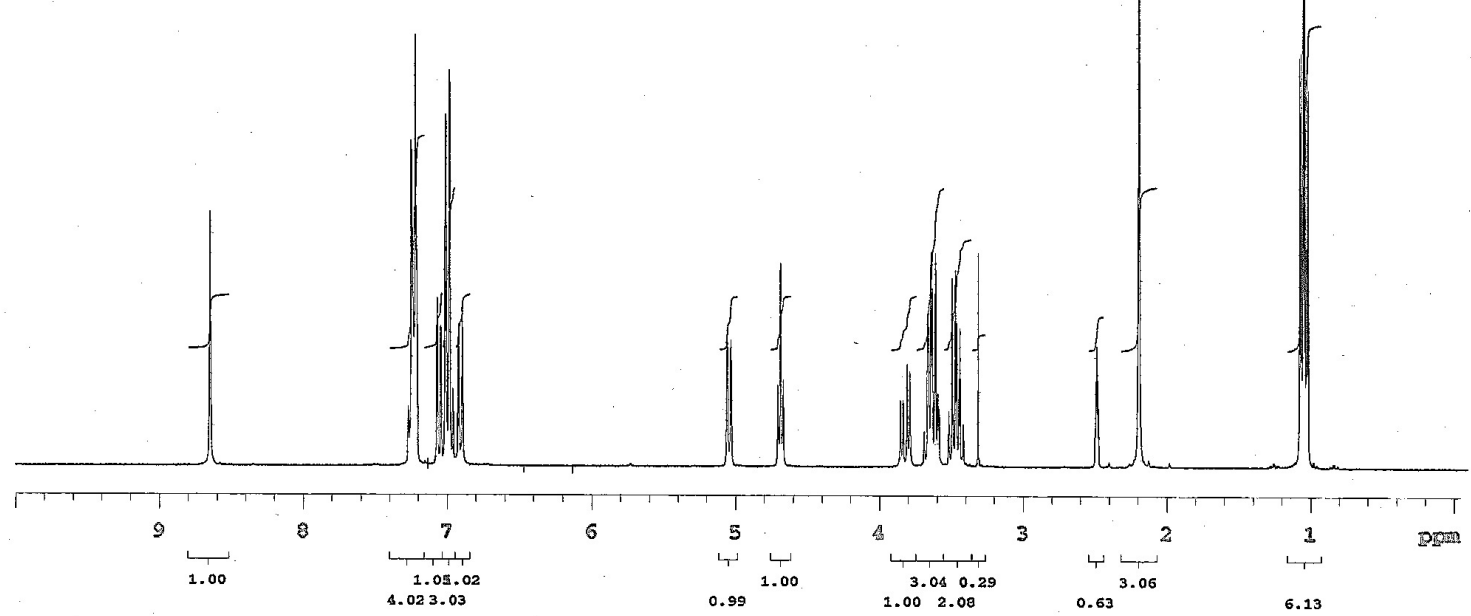

\begin{tabular}{|c|c|c|c|}
\hline \multicolumn{3}{|c|}{ 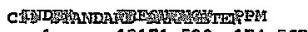 } & HEI GHT \\
\hline & $\begin{array}{r}13171.520 \\
11634.555\end{array}$ & $\begin{array}{l}174.567 \\
154.197\end{array}$ & $\begin{array}{r}34.3 \\
82.1\end{array}$ \\
\hline Pul बुำ & 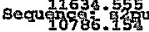 & $\begin{array}{l}1.24 .971 \\
142.953\end{array}$ & \\
\hline 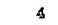 & 10346.312 & 137.124 & 39.1 \\
\hline 5 & 9794.699 & 129.813 & 39.2 \\
\hline 6 & 9710.774 & 128.701 & 82.1 \\
\hline 7 & 9637.912 & 127.735 & 35.1 \\
\hline 8 & 9616.550 & 327.452 & 39.3 \\
\hline 9 & 9272.077 & 122.896 & 29.4 \\
\hline 10 & 9174.419 & 121.592 & 35.8 \\
\hline 11 & 8871.909 & 117.593 & 83.0 \\
\hline 12 & 9224.164 & 308.998 & 28.9 \\
\hline 13 & 7502.031 & 99.427 & 37.1 \\
\hline 11 & $\$ 701.619$ & 62.312 & $\$ 1.7$ \\
\hline 15 & 4680.256 & 62.029 & 46.8 \\
\hline 16 & 3948.204 & 52.327 & 35,4 \\
\hline 17 & $32 \$ 1.712$ & 42.966 & 28.4 \\
\hline 18 & 3037.622 & so. & 22.4 \\
\hline 19 & 3016.641 & 39. & 60.9 \\
\hline 20 & 2995. & 39. & 28.4 \\
\hline 21 & 2974.679 & 39.425 & 49.6 \\
\hline 22 & 2953.698 & 39.1 & 128.1 \\
\hline 23 & 2932.717 & 38. & 62.9 \\
\hline 24 & 2912.117 & & 23.1 \\
\hline 25 & 1525.453 & 20.217 & 50.4 \\
\hline 26 & 1144.741 & 25.172 & 87.0 \\
\hline
\end{tabular}

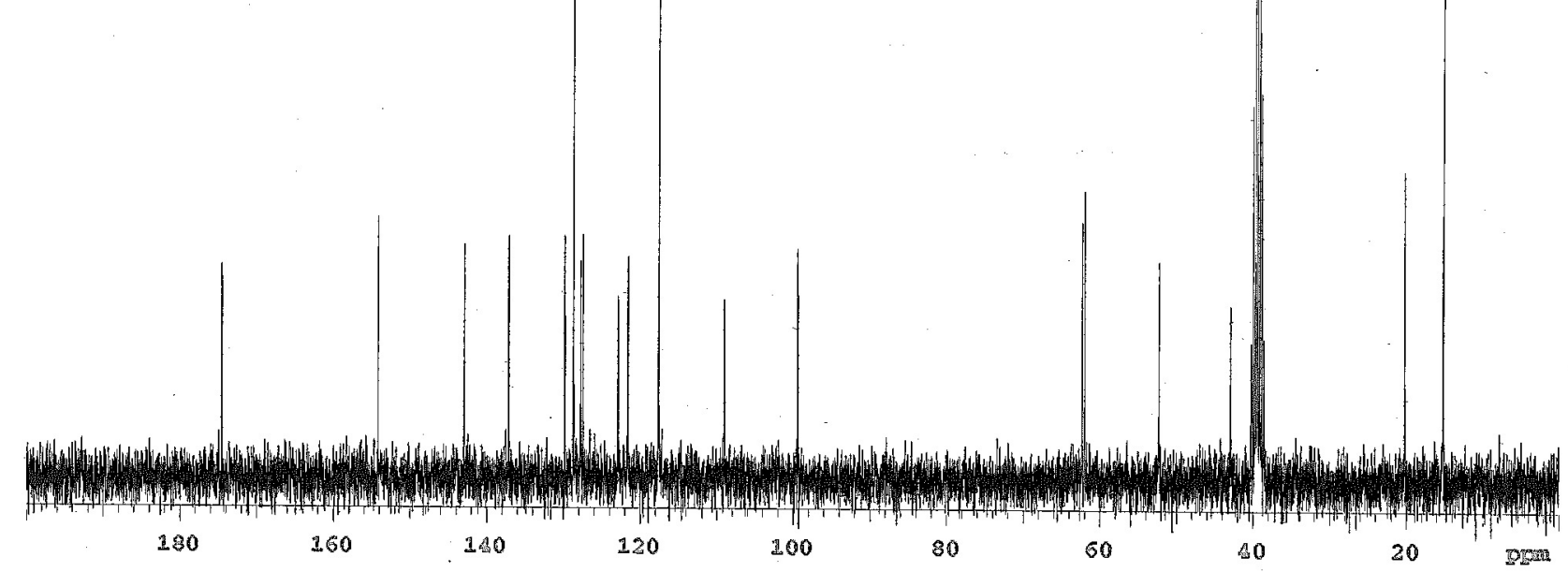


MIE1-75-pure

Fulse sequence: a2pul<smiles>CON=C1C(=O)Nc2ccccc21</smiles>

6

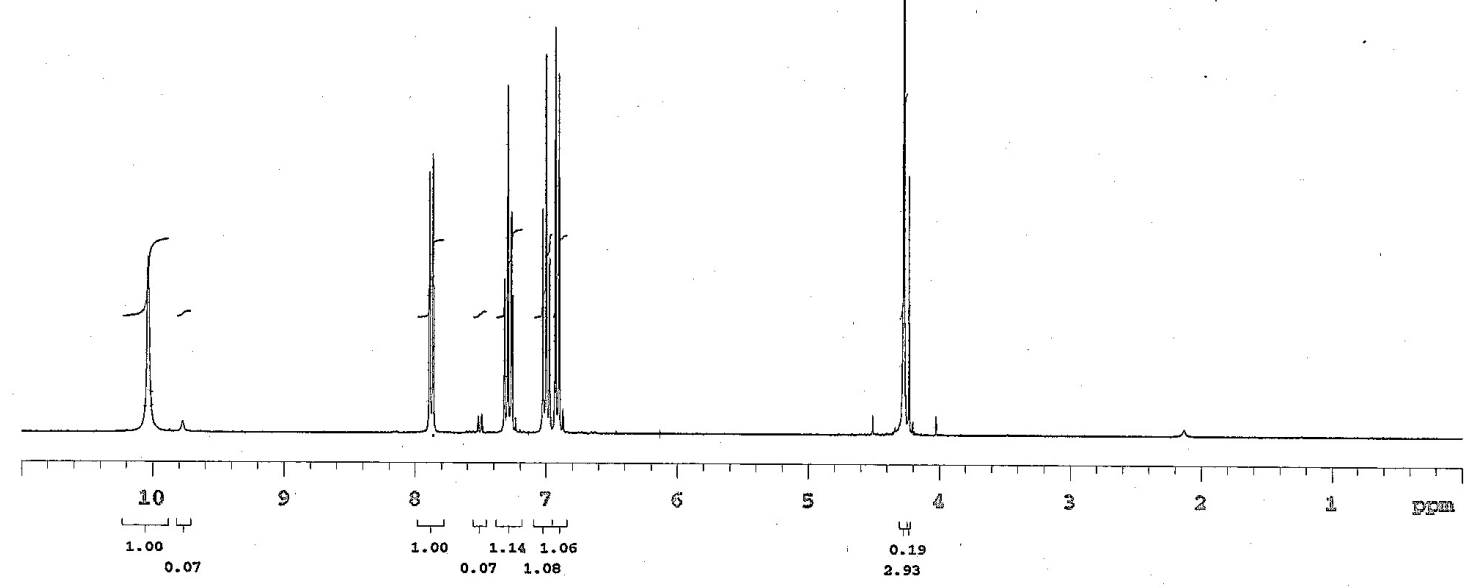

C13 ITRADARD BRRAMUITER

Fu1 ae sequence: a2pux

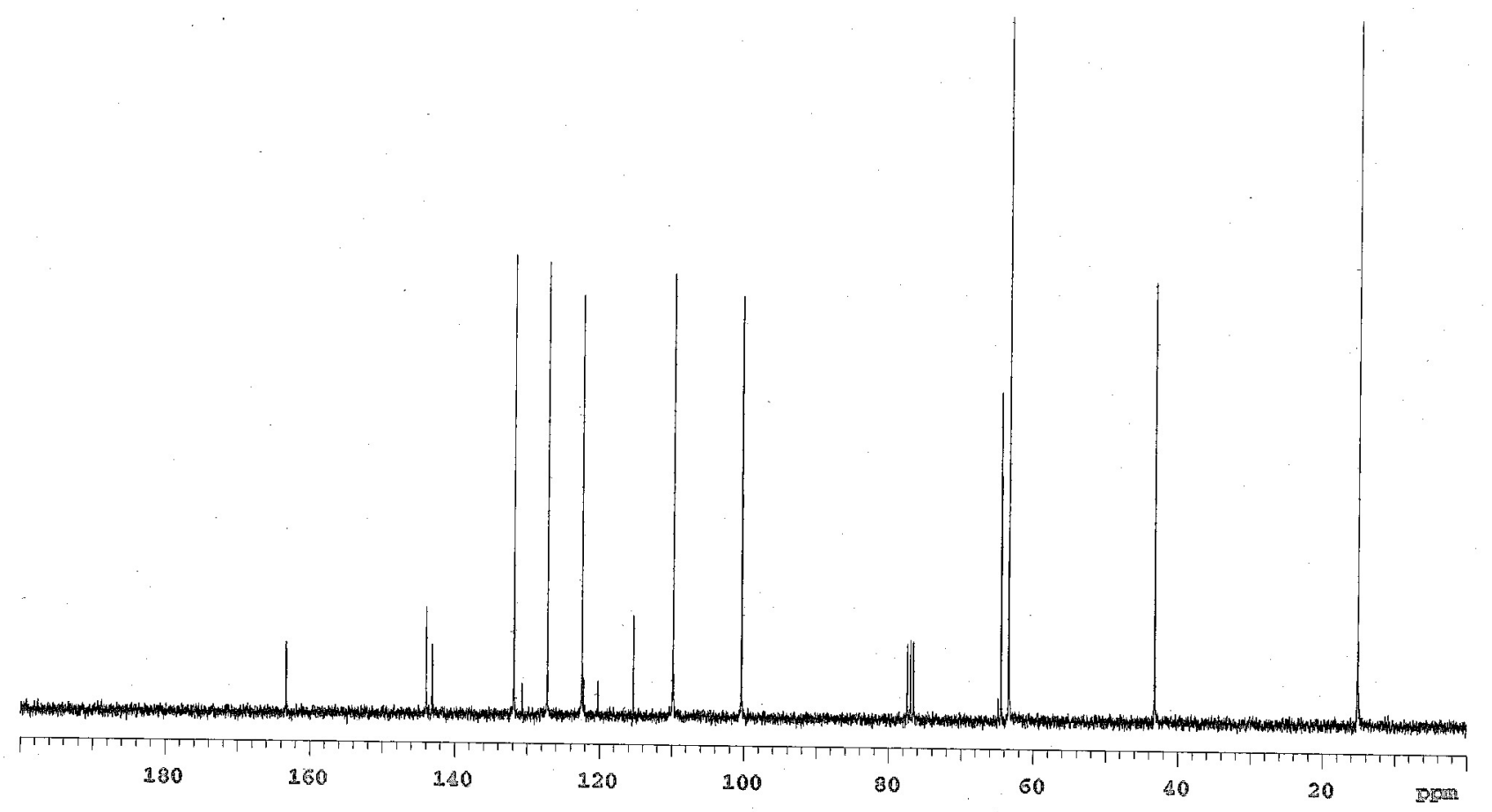




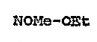

Pulse sequenco: s2pu1<smiles>CCOC(CN1C(=O)C(=NOC)c2ccccc21)OCC</smiles>

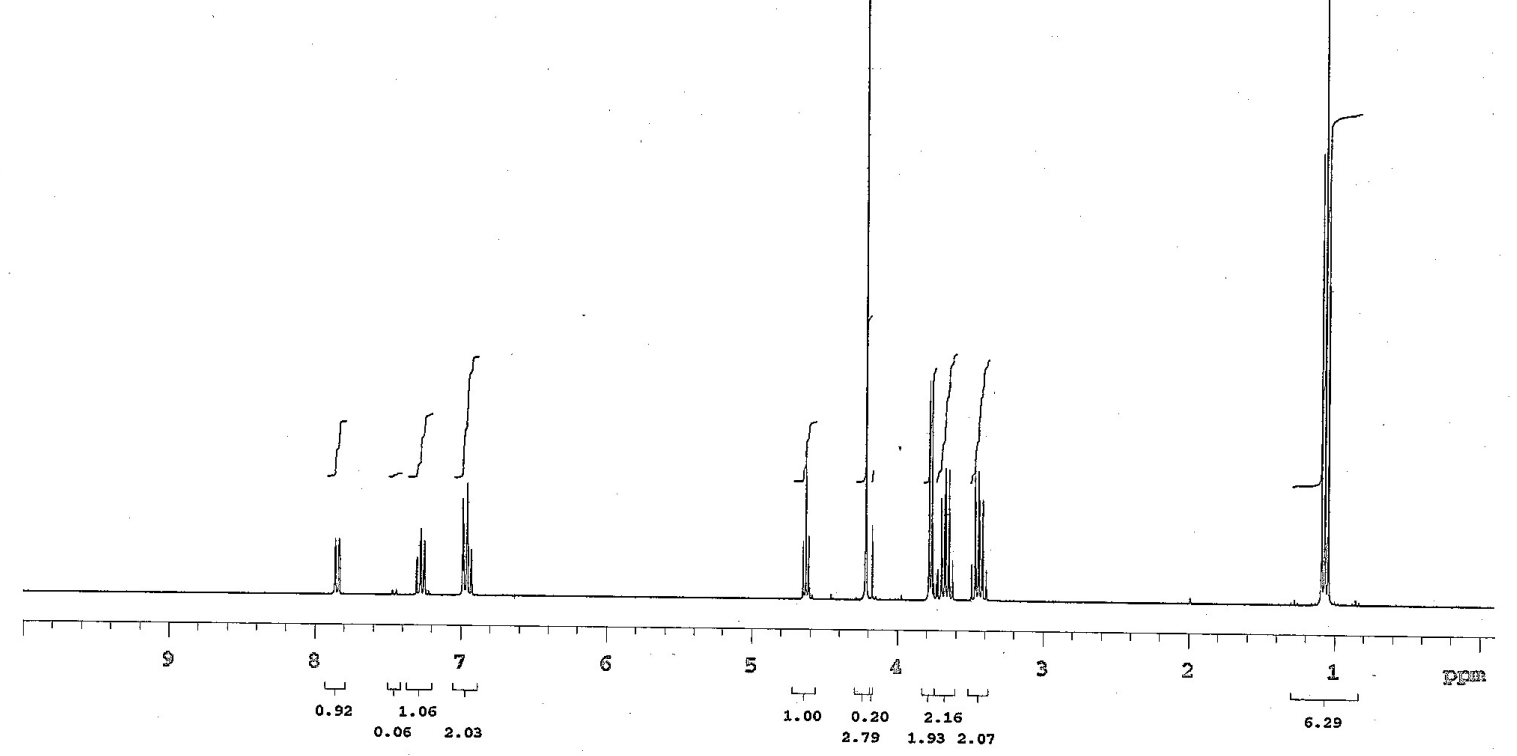

C13 STANDARD RARAMEITRR

pu1se Bequance: \&2pu1

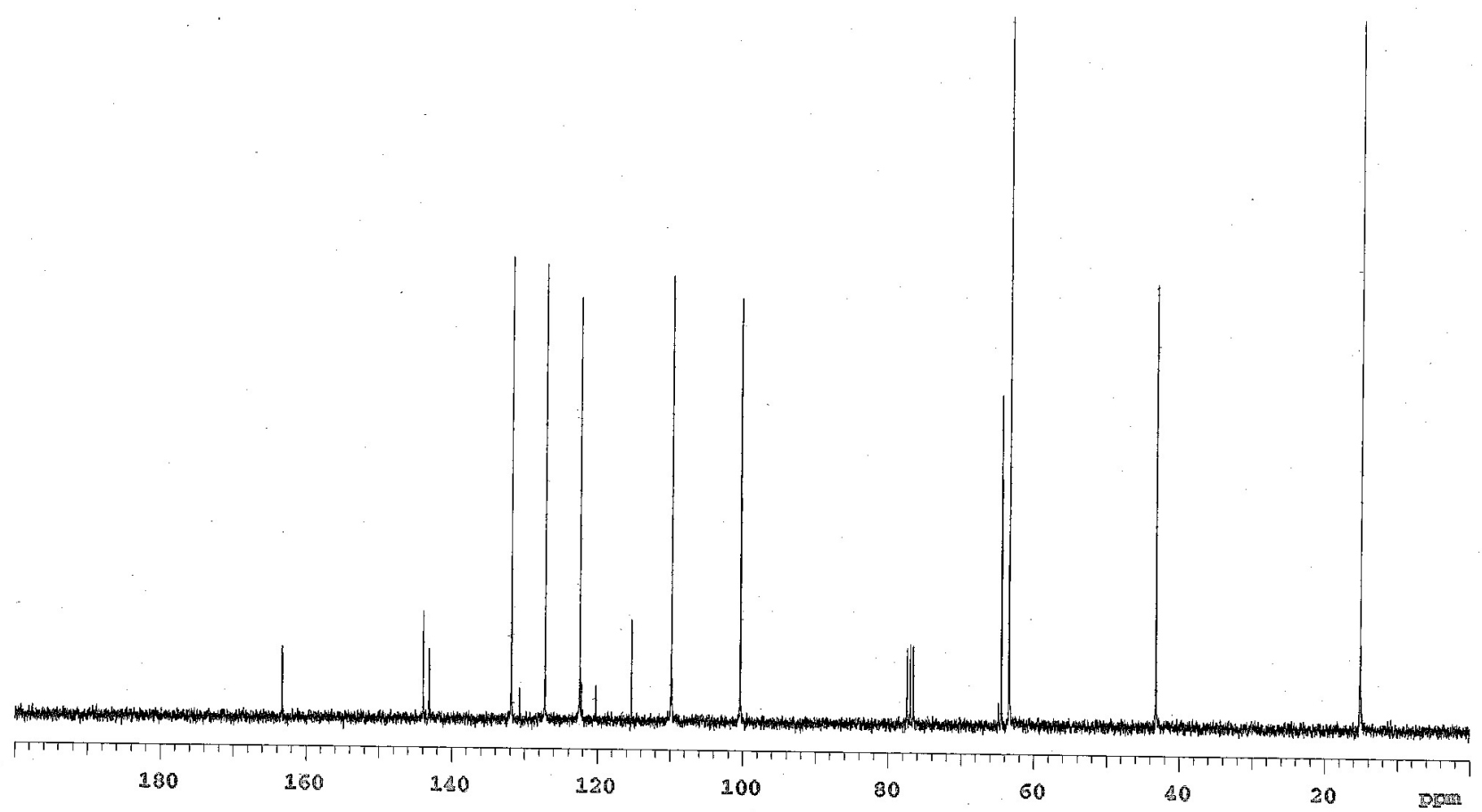



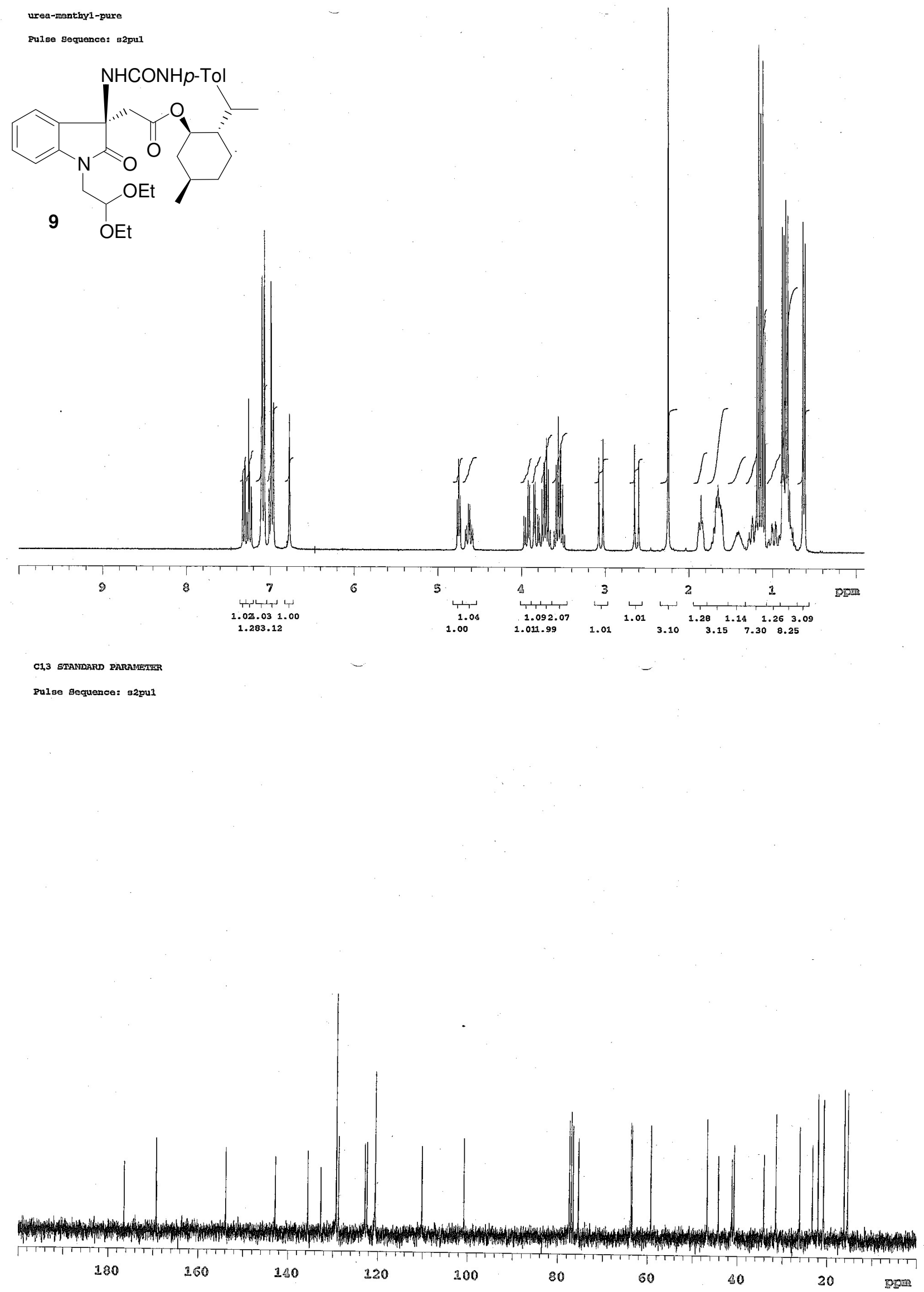

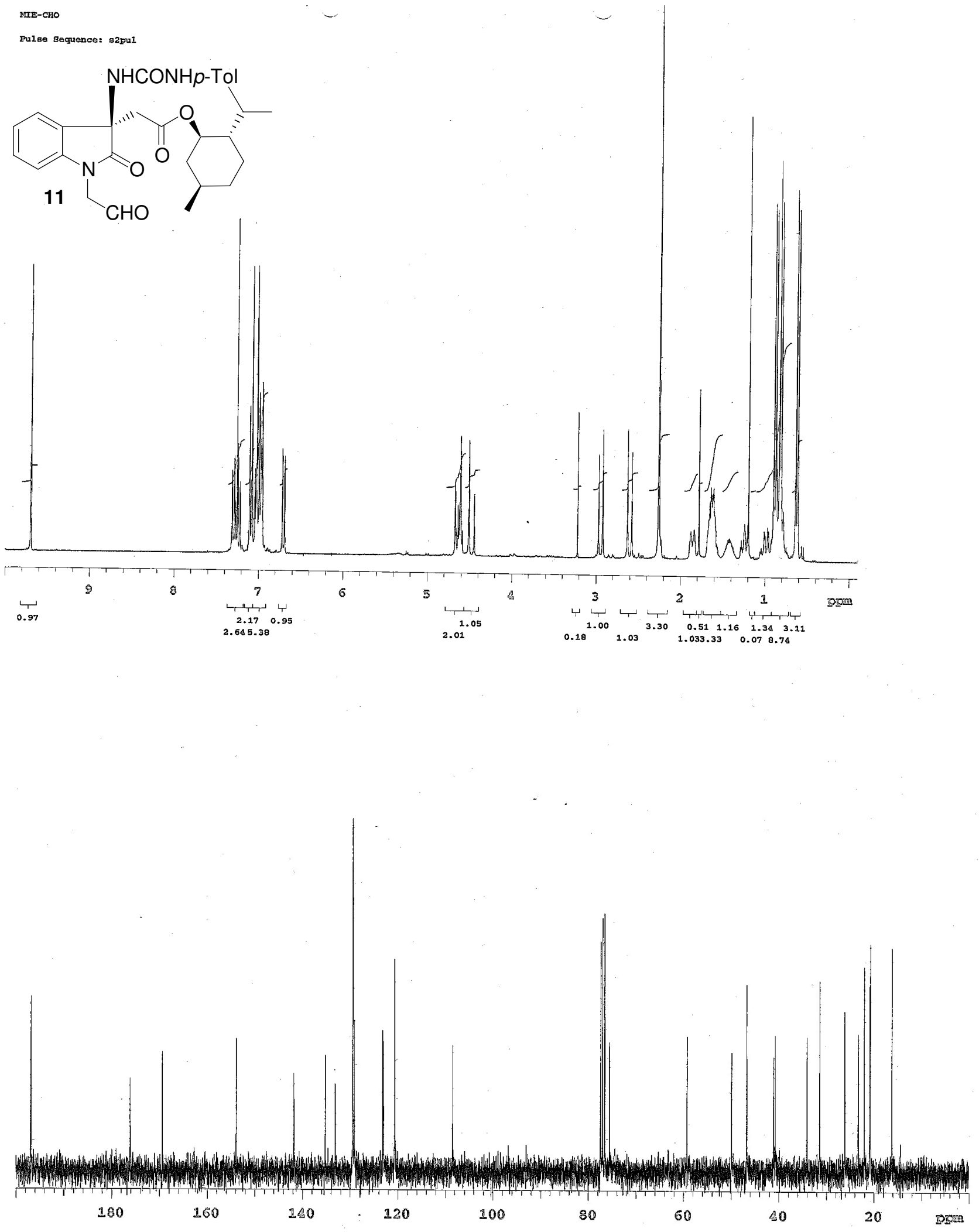


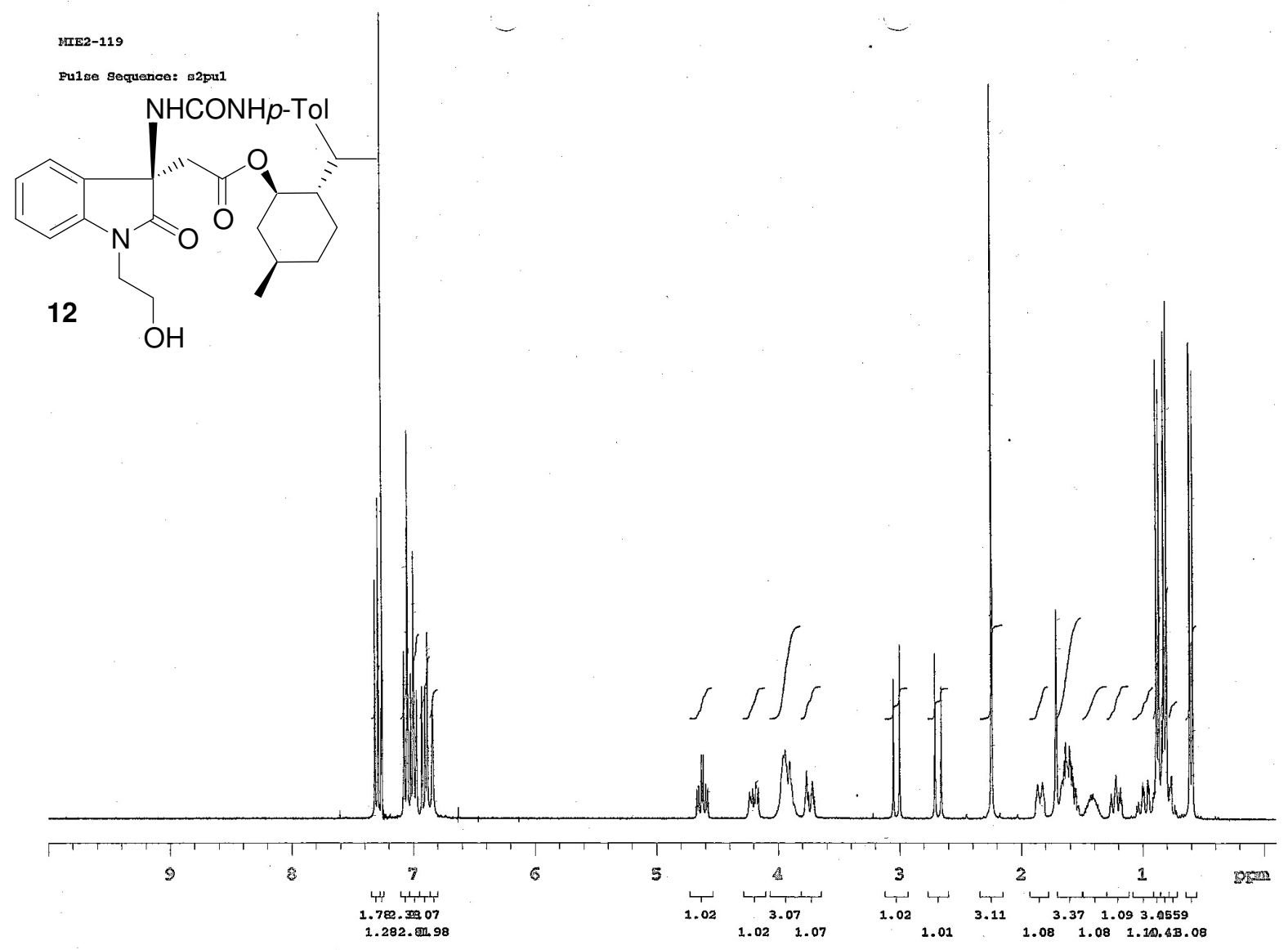

C13 EIMARDARD PARAMETER

Fulse aequance: ब2pul

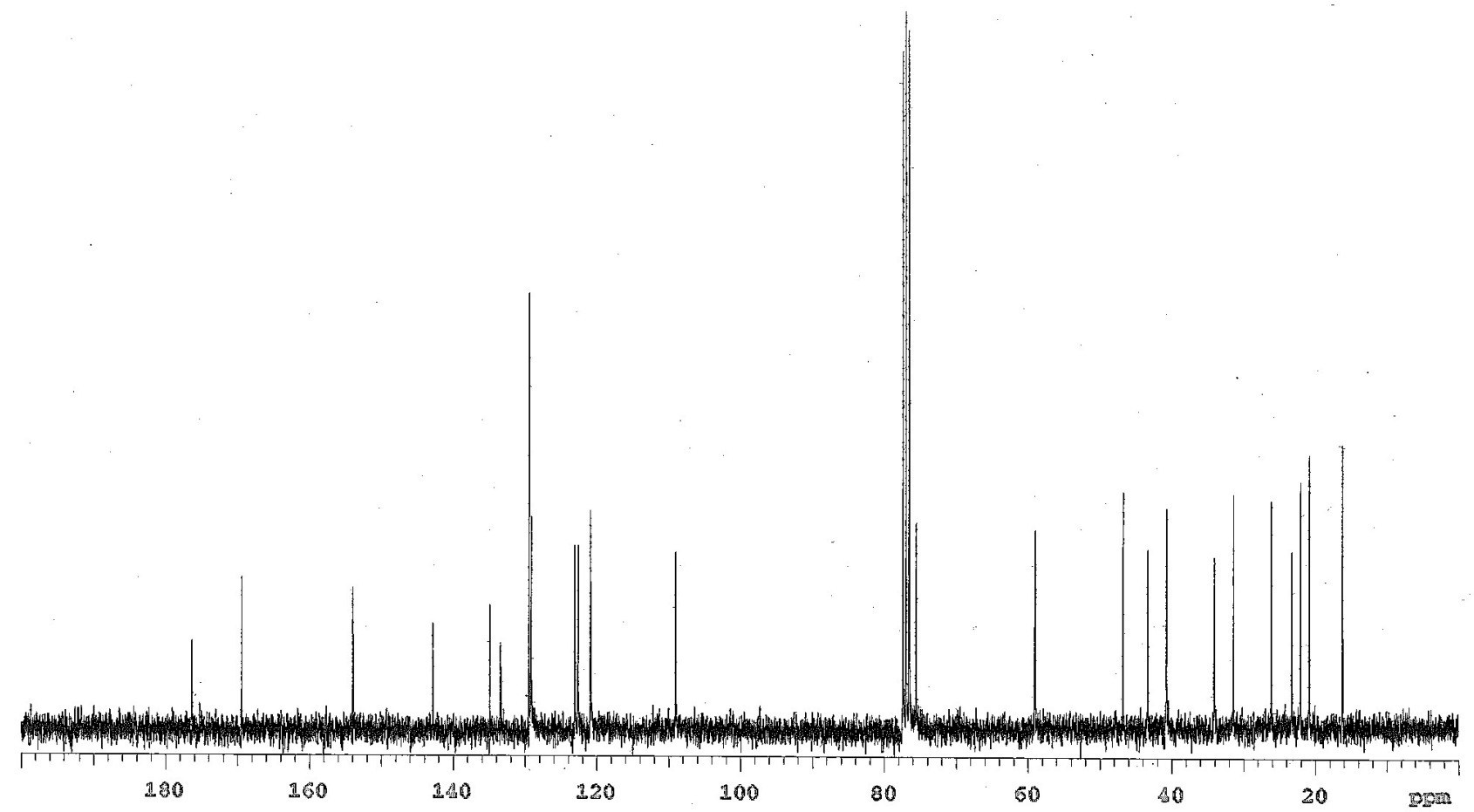


3IE1-66-pure

Fulse sequenco: s2pul<smiles>Cc1ccc(NC(=O)NC2C(=O)N(C)c3ccccc32)cc1</smiles>

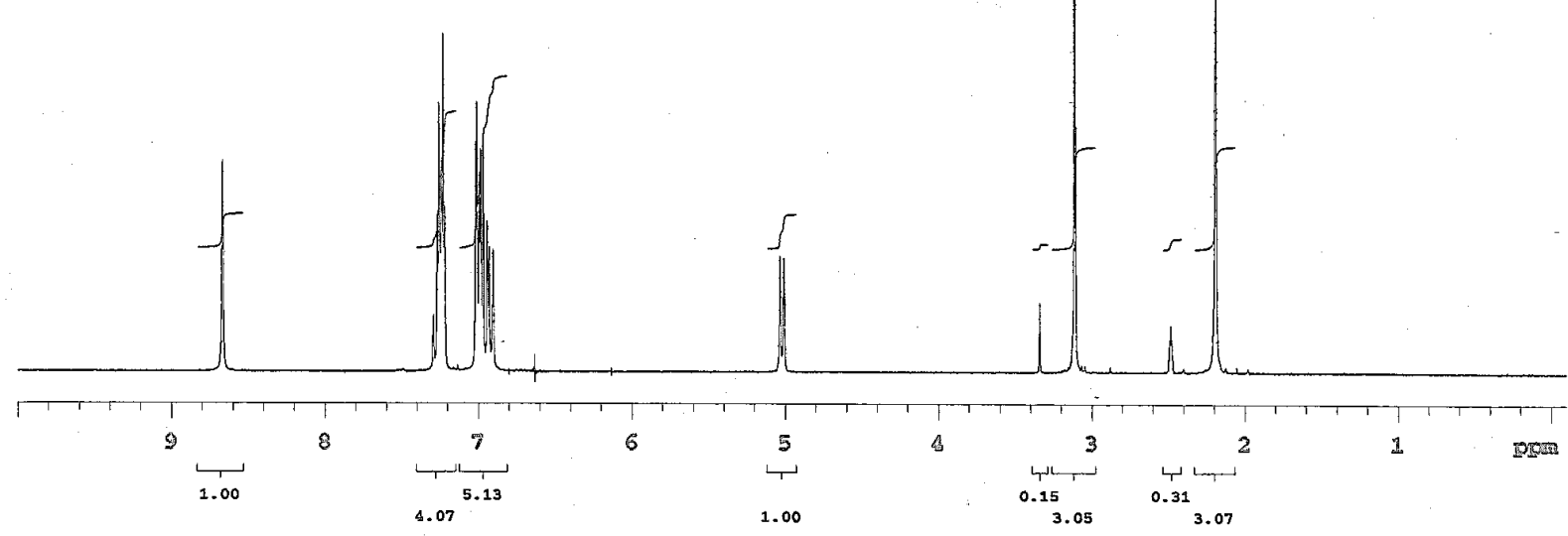

C13 STANDARD PARAVIETERR

Pulso sequenco: s2pul

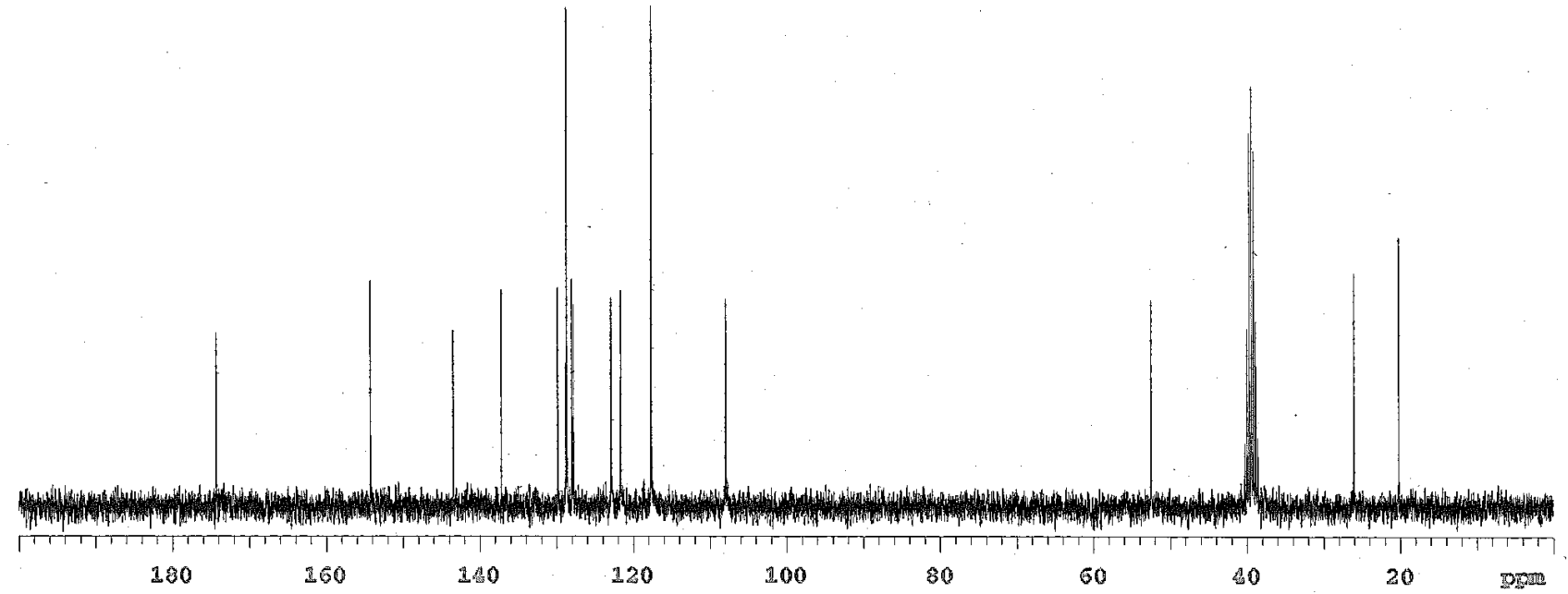



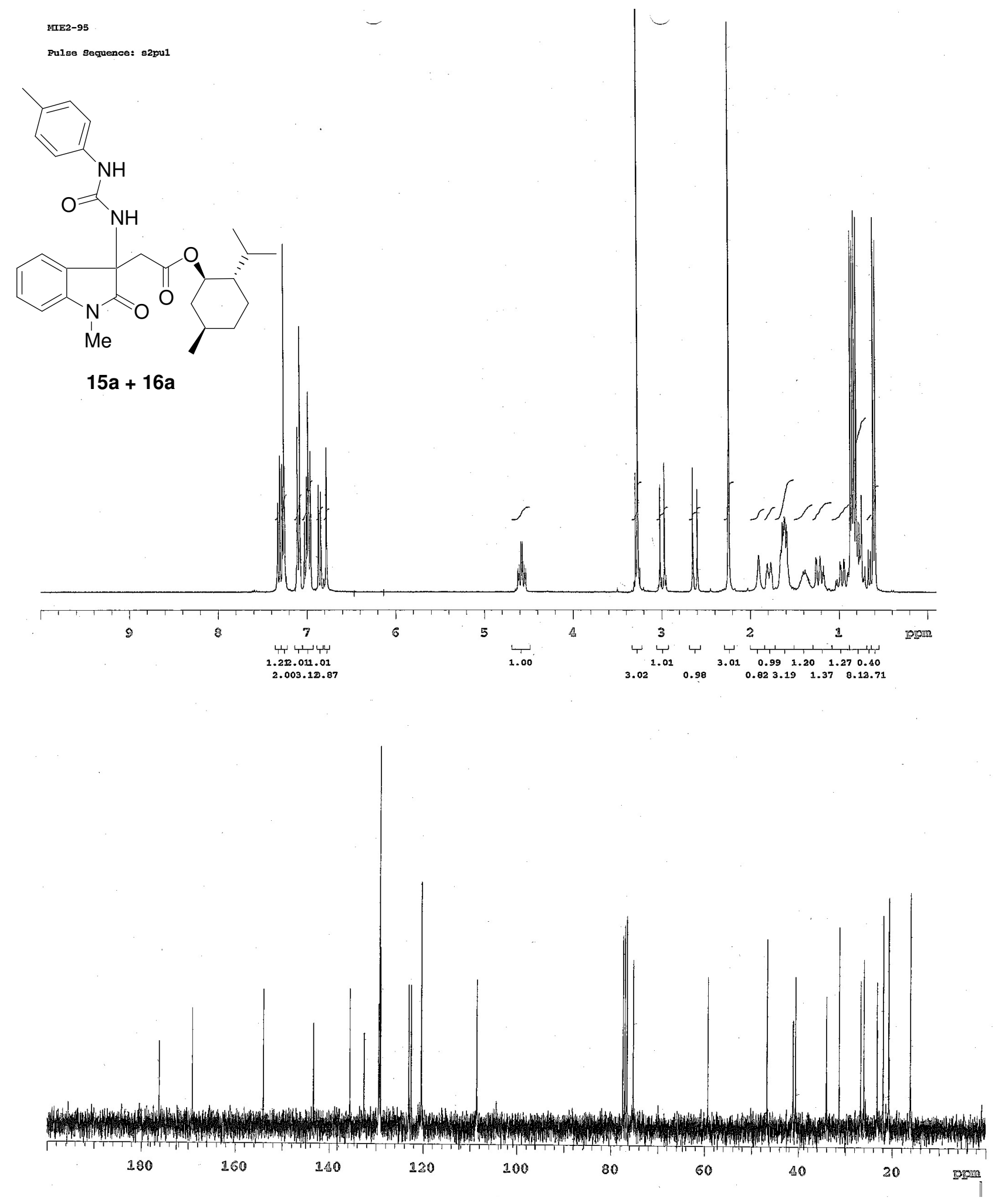

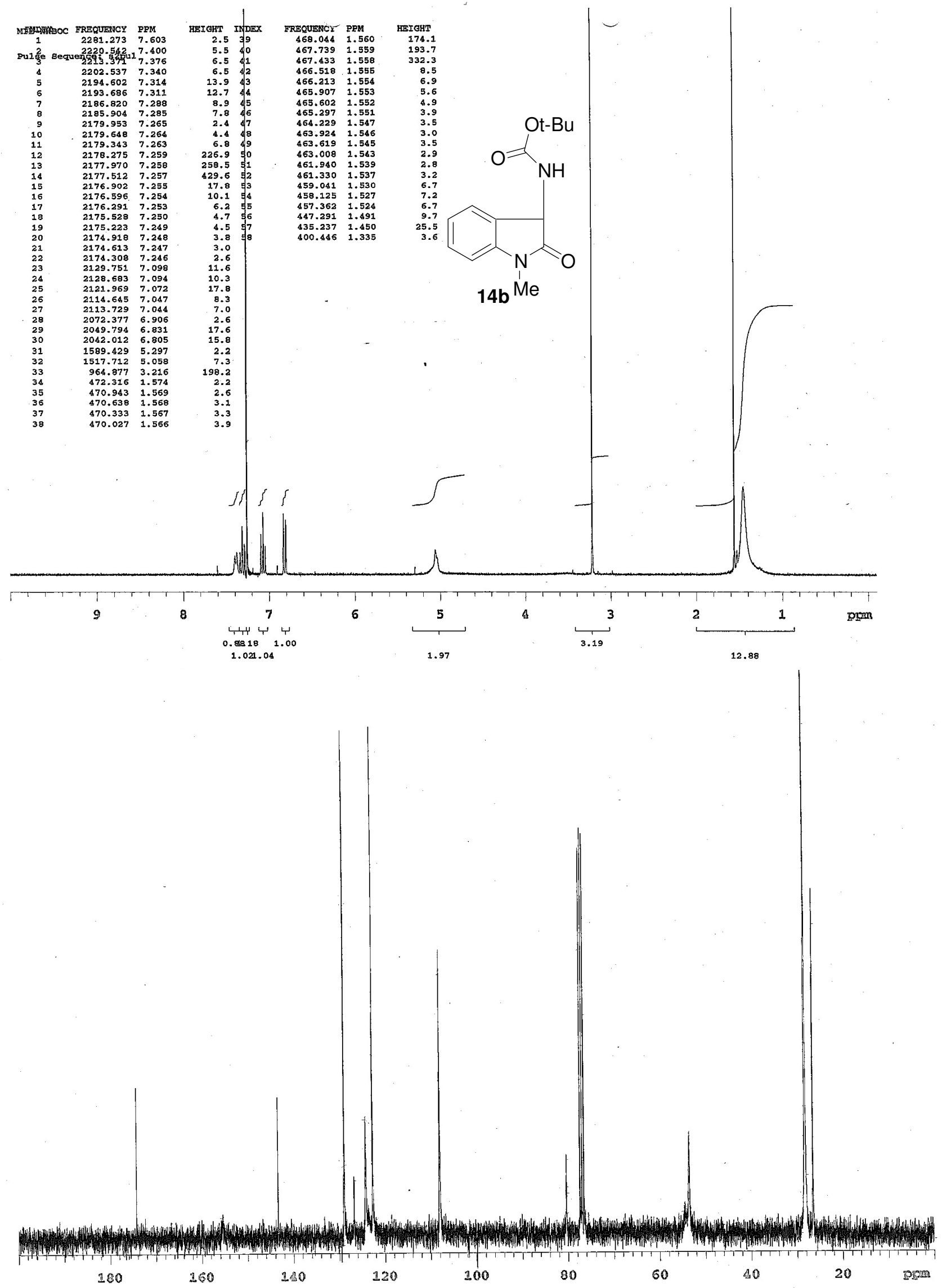
BIE2-112

Pu1.ee sequence: $\$ 2$ pul<smiles>CCC(C)OC(=O)N[C@]1(CC(=O)O[C@H]2C[C@H](C)CC[C@H]2C(C)C)C(=O)N(C)c2ccccc21</smiles>

$15 b+16 b$
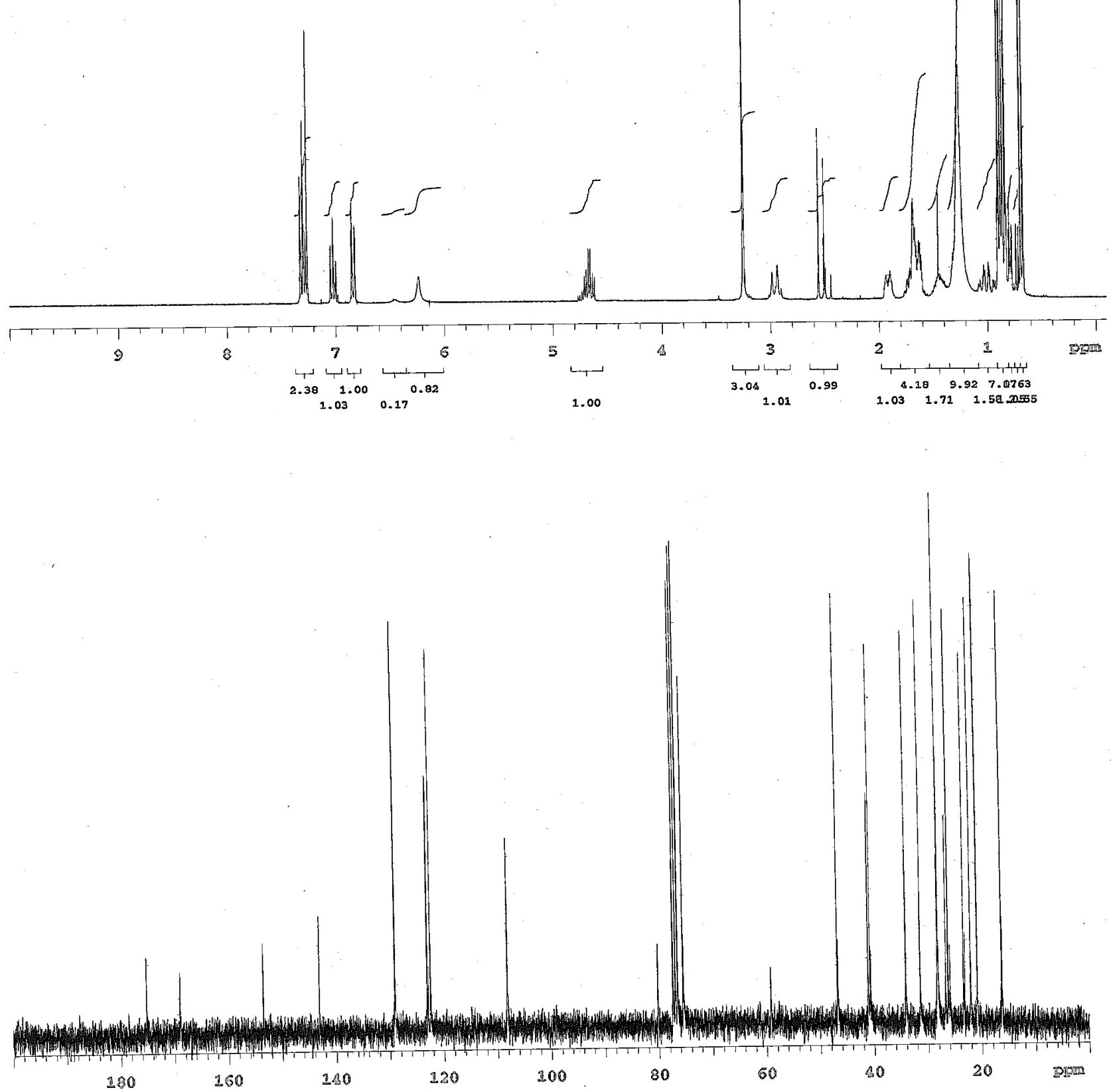


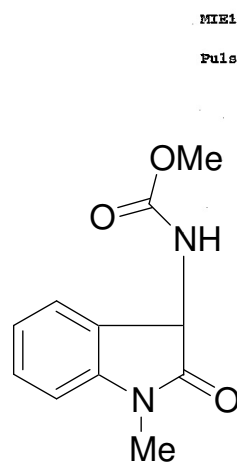

1IE1-36-pure

pu1se sequence: \&2pu1

$$
14 \mathrm{c}
$$

C13 ITAMIDARD PARAMETER

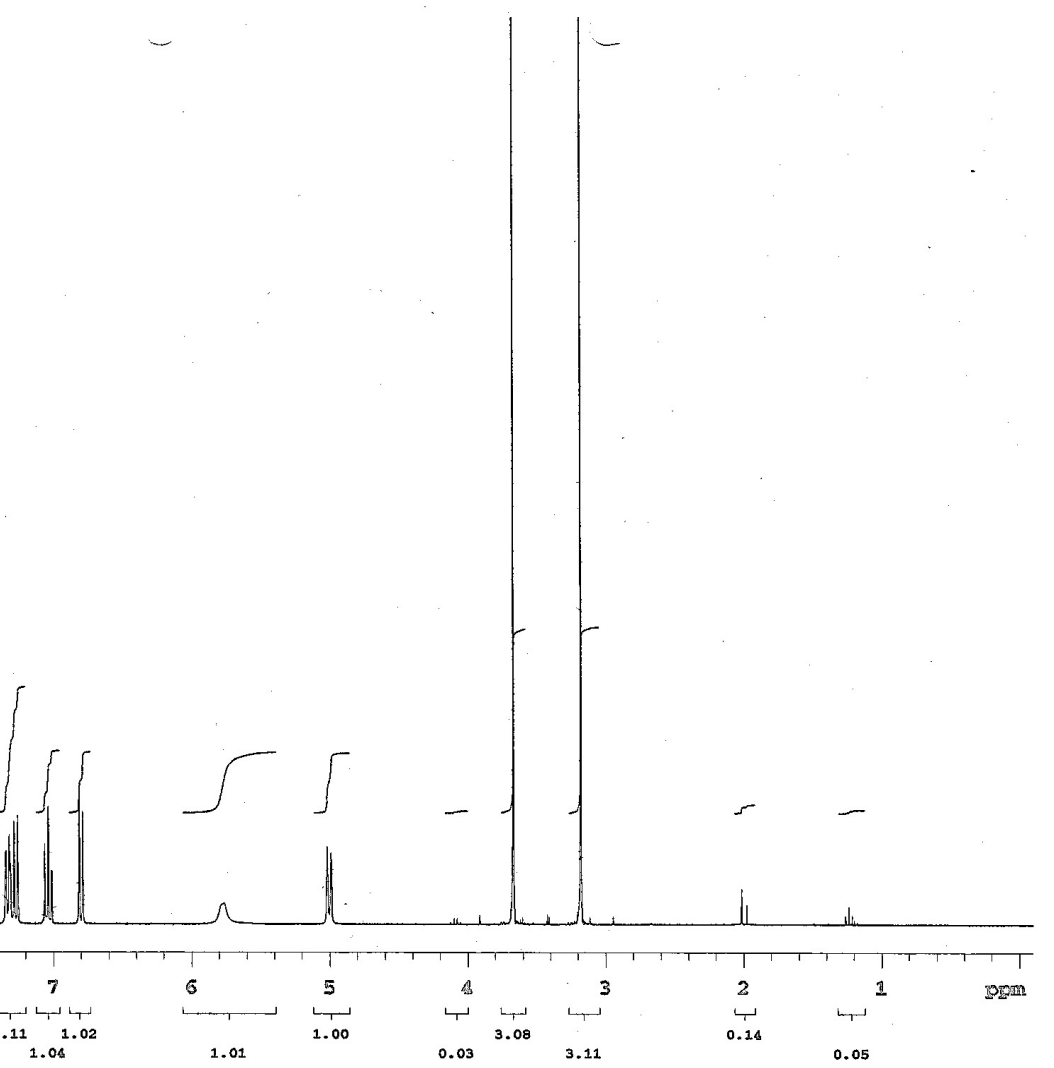

Pu1se Saquence: E2pul

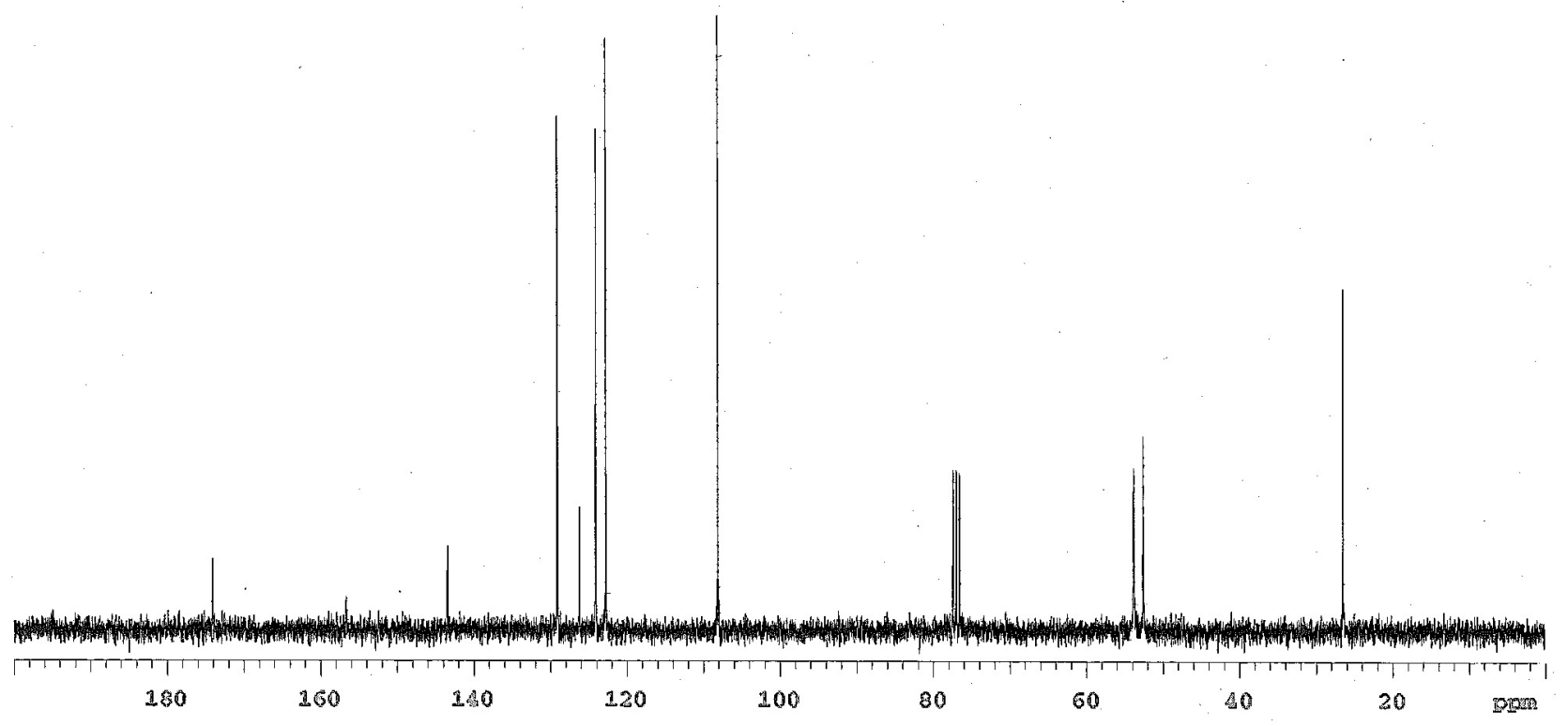



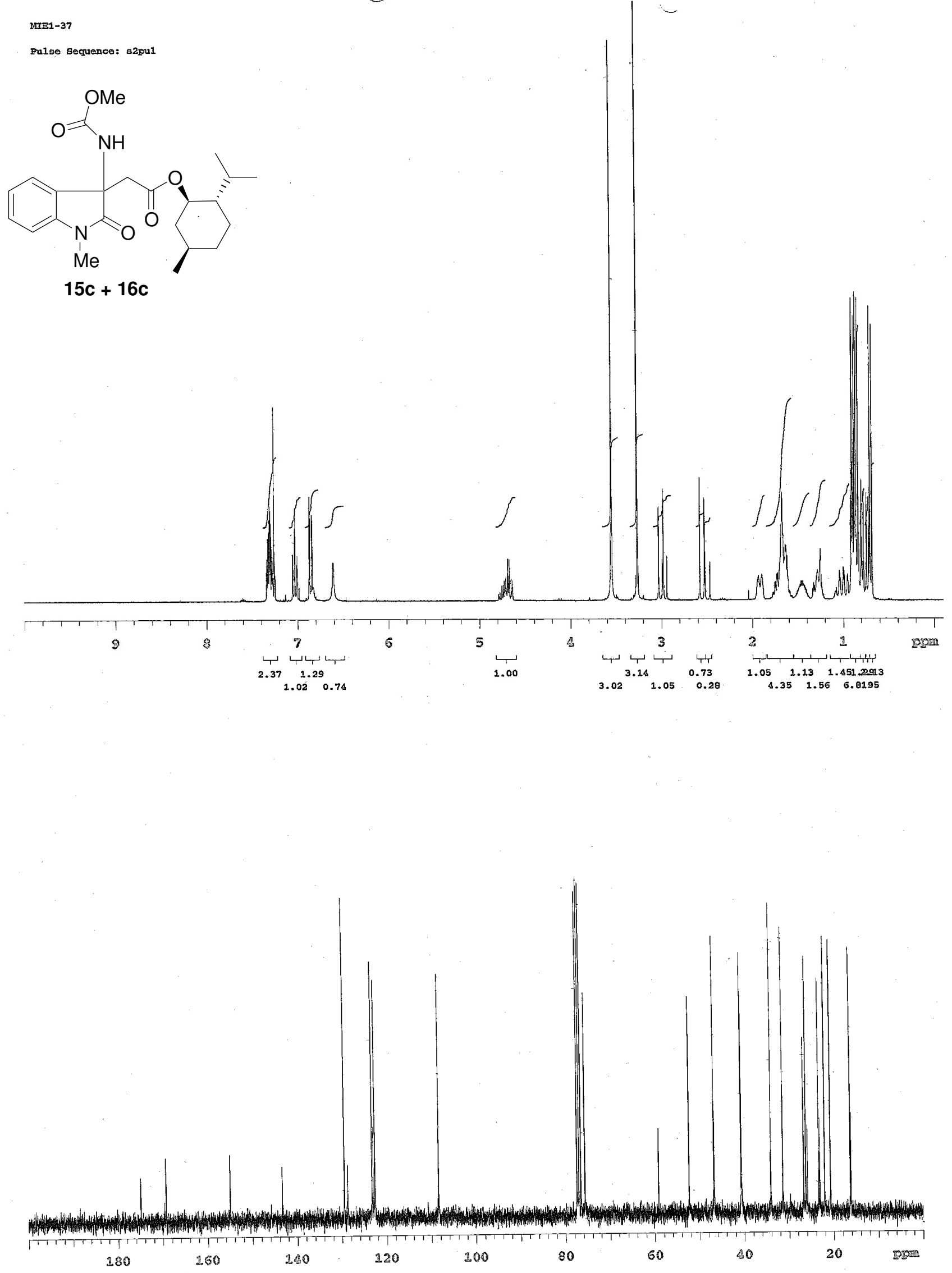


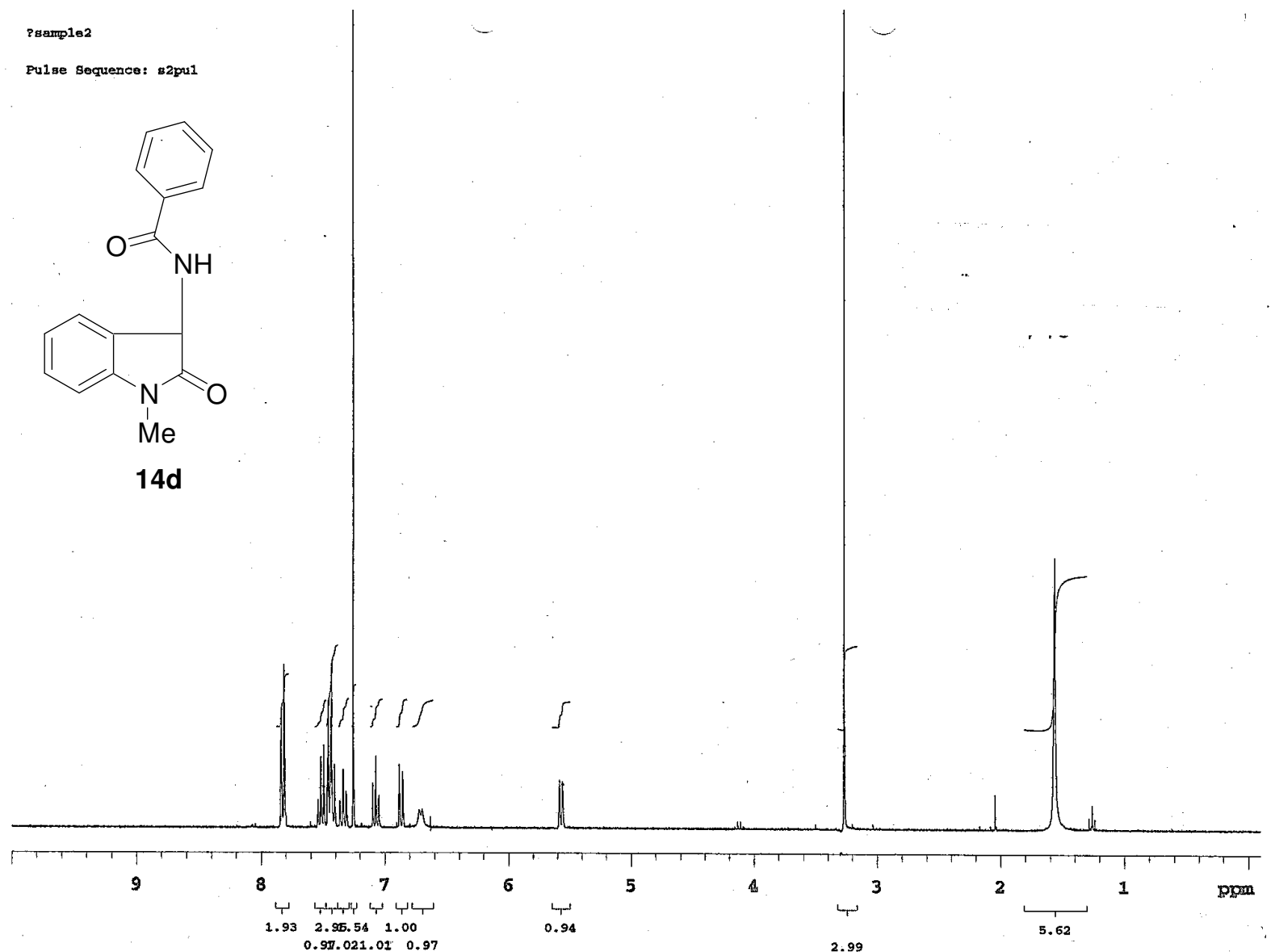

IIIE1-32-pure

Fulse Baquence: 82pul

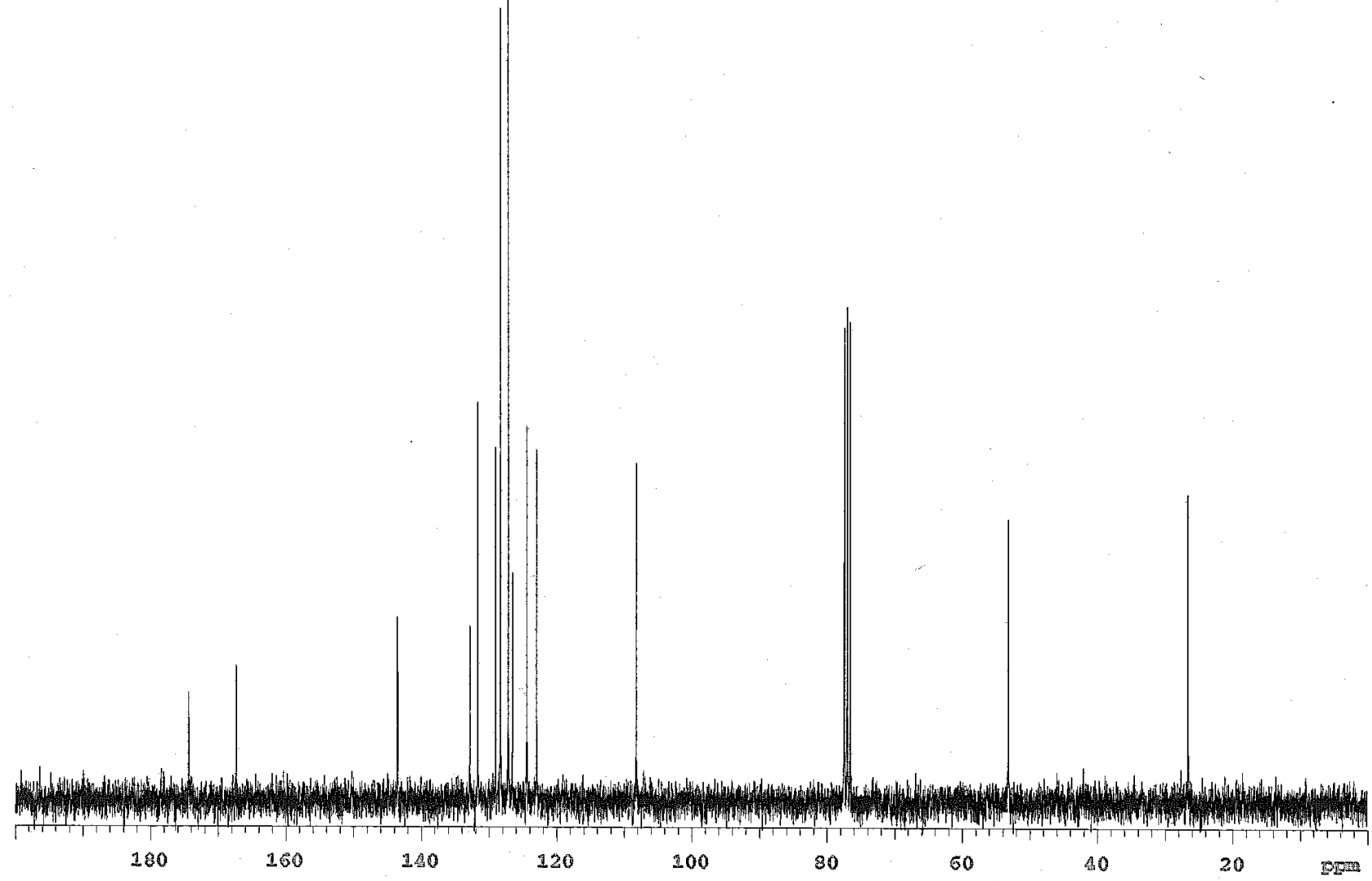



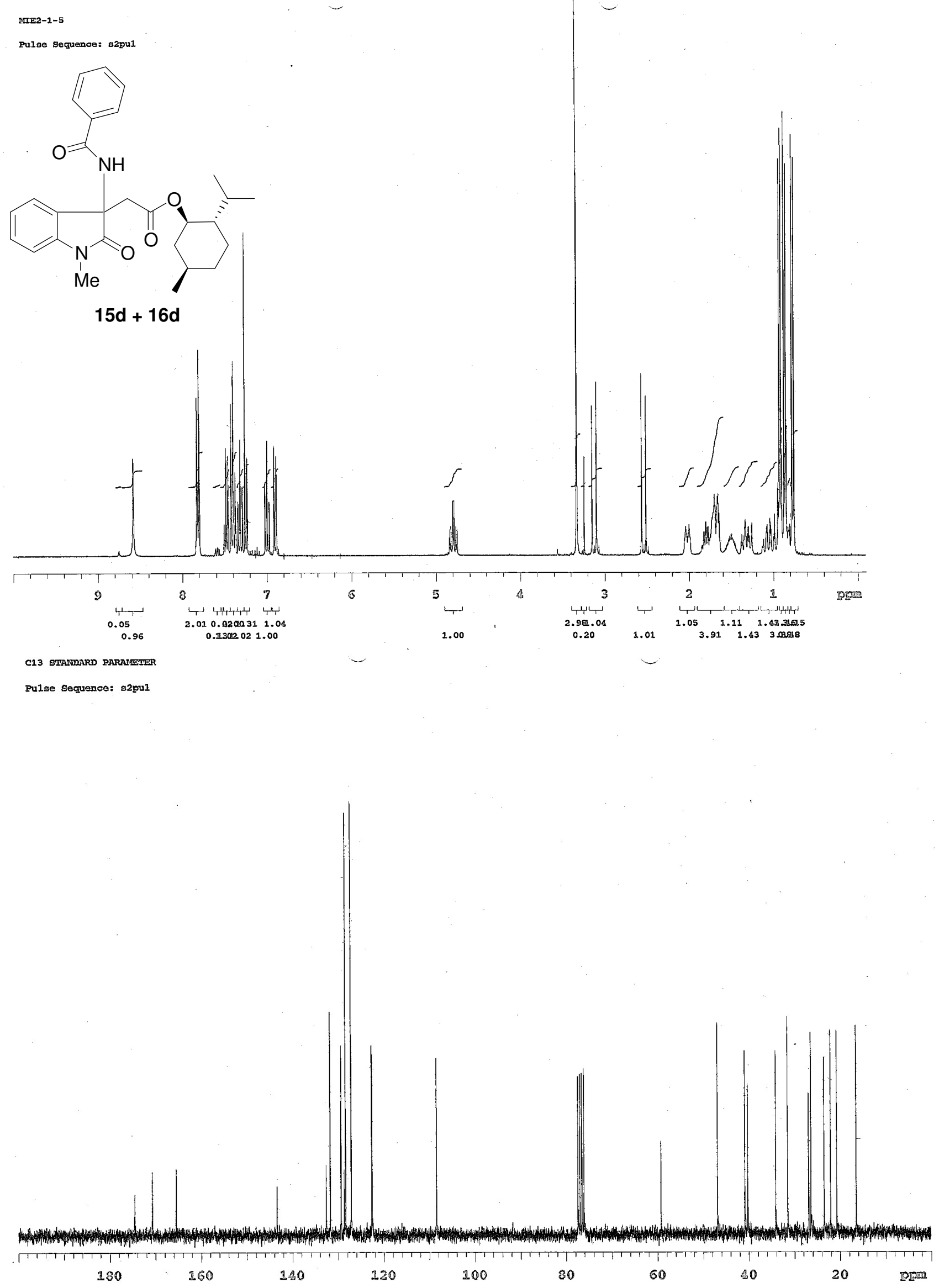

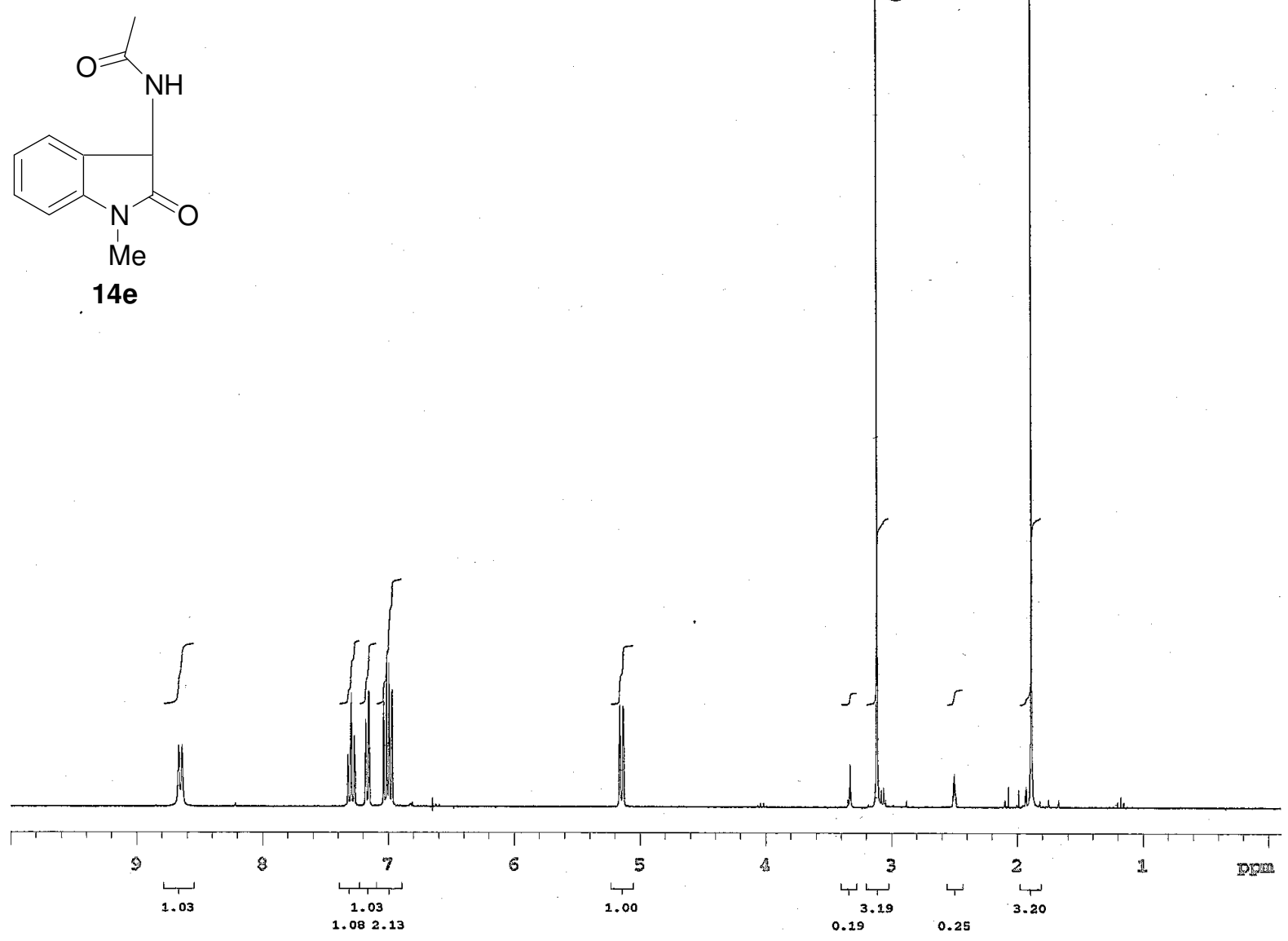

MLE1-33-pure

Pulse sequenco: a2pul

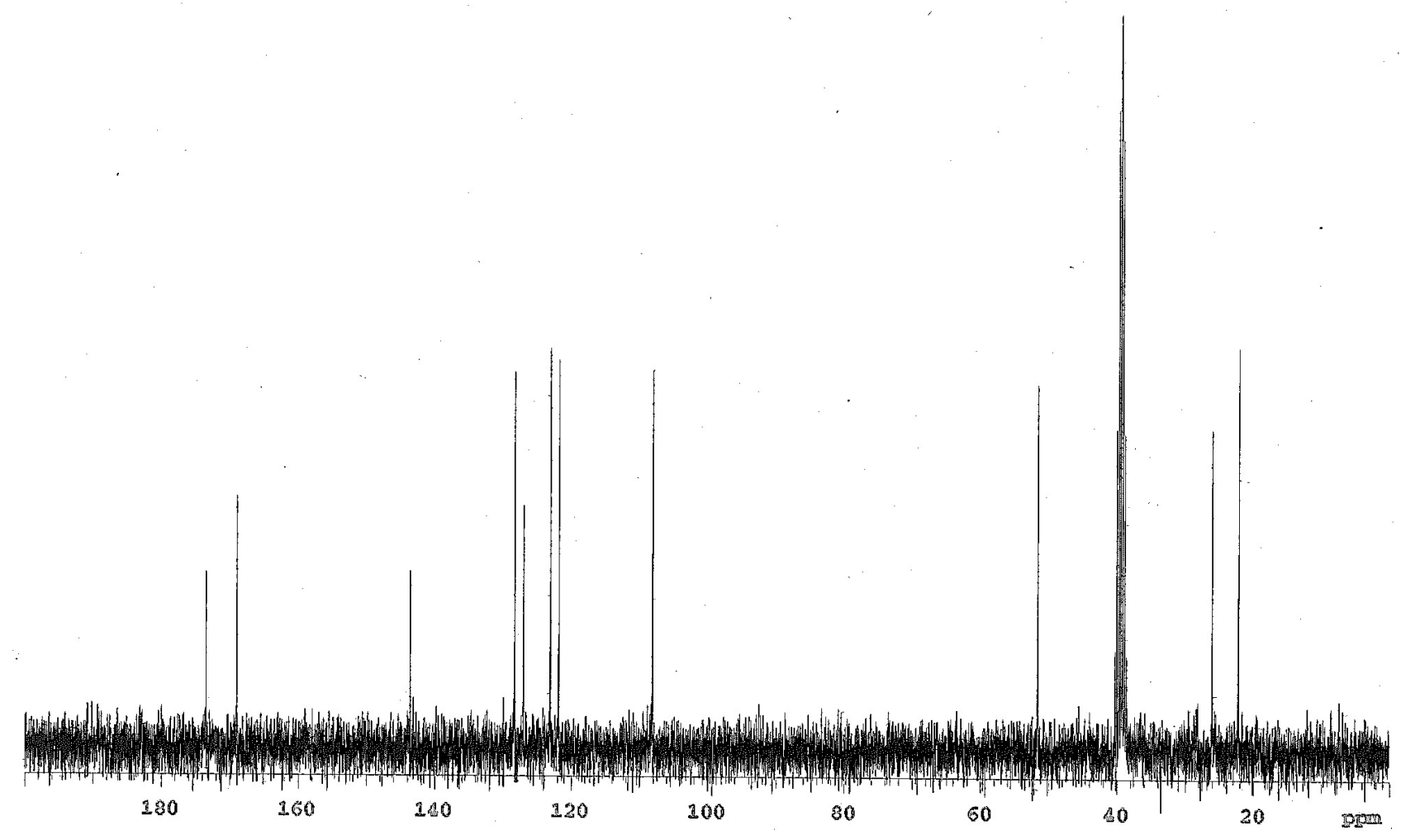



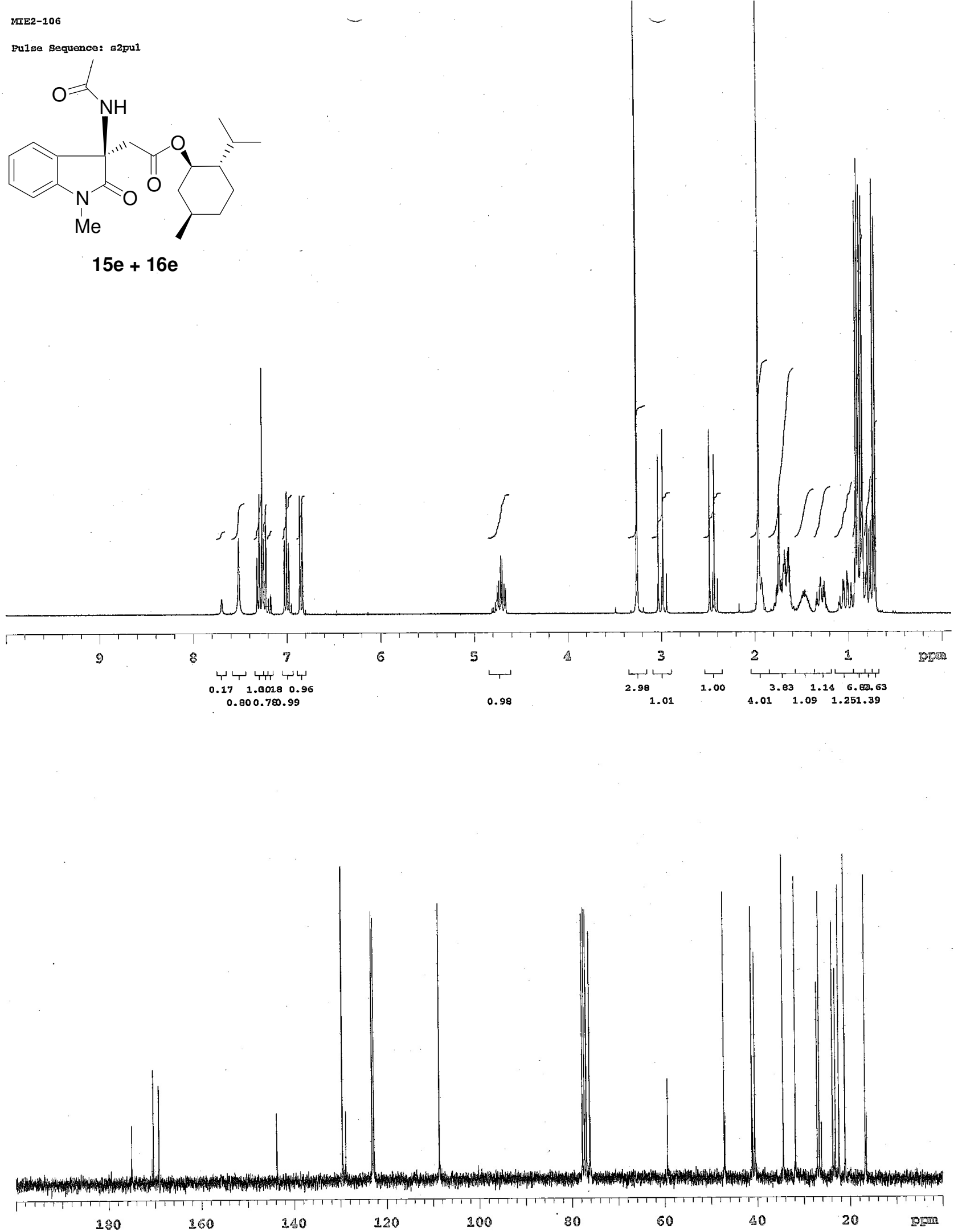